OAK RIDGE

NATIONAL LABORATORY

MANAGED BY UT-BATTELLE

FOR THE DEPARTMENT OF ENERGY

\title{
Evaluation of Manufacturability of Embedded Sensors and Controls with Canned Rotor Pump System
}

July 2013

Prepared by

R. Kisner,

D. Fugate,

A. Melin,

D. Holcomb,

D. Wilson,

P. Silva,

C. Cruz Molina

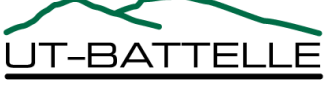




\section{DOCUMENT AVAILABILITY}

Reports produced after January 1, 1996, are generally available free via the U.S. Department of Energy (DOE) Information Bridge.

Web site http://www.osti.gov/bridge

Reports produced before January 1, 1996, may be purchased by members of the public from the following source.

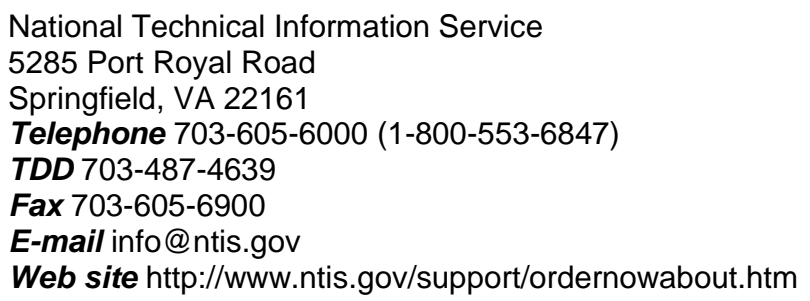

Reports are available to DOE employees, DOE contractors, Energy Technology Data Exchange (ETDE) representatives, and International Nuclear Information System (INIS) representatives from the following source.

Office of Scientific and Technical Information

P.O. Box 62

Oak Ridge, TN 37831

Telephone 865-576-8401

Fax 865-576-5728

E-mail reports@osti.gov

Web site http://www.osti.gov/contact.html

This report was prepared as an account of work sponsored by an agency of the United States Government. Neither the United States Government nor any agency thereof, nor any of their employees, makes any warranty, express or implied, or assumes any legal liability or responsibility for the accuracy, completeness, or usefulness of any information, apparatus, product, or process disclosed, or represents that its use would not infringe privately owned rights. Reference herein to any specific commercial product, process, or service by trade name, trademark, manufacturer, or otherwise, does not necessarily constitute or imply its endorsement, recommendation, or favoring by the United States Government or any agency thereof. The views and opinions of authors expressed herein do not necessarily state or reflect those of the United States Government or any agency thereof. 


\title{
EVALUATION OF MANUFACTURABILITY OF EMBEDDED SENSORS AND CONTROLS WITH CANNED ROTOR PUMP SYSTEM
}

\author{
R. Kisner, \\ D. Fugate, \\ A. Melin, \\ D. Holcomb, \\ D. Wilson, \\ P. Silva, \\ C. Cruz Molina
}

Date Published: July 2013

Prepared by

OAK RIDGE NATIONAL LABORATORY

Oak Ridge, Tennessee 37831-6283

managed by

UT-BATTELLE, LLC

for the

U.S. DEPARTMENT OF ENERGY

under contract DE-AC05-00OR22725 



\section{CONTENTS}

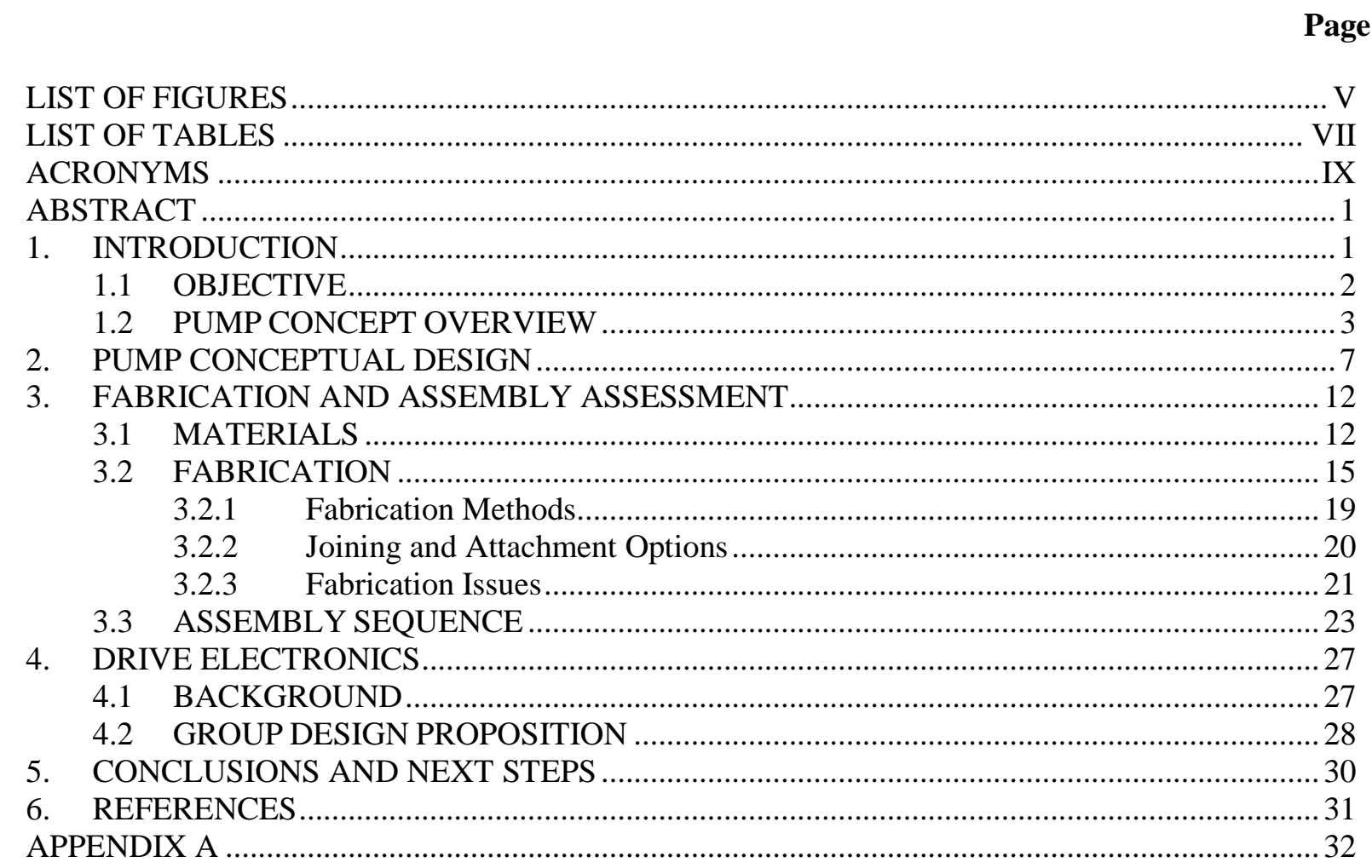




\section{LIST OF FIGURES}

Figure

Page

Figure 1. Reference illustration of canned rotor motor with pump impeller.............................................. 3

Figure 2. Cross section of motor bearing showing gap location. ............................................................

Figure 3. Illustration of materials stack in motor (not to scale). ................................................................

Figure 4. Simplified system control electronics block diagram. ..................................................... 6

Figure 5. Major component groups (rotor, stator, coupler, and end cap) color coded. ............................. 7

Figure 6. Rotating versus stationary components color coded.........................................................

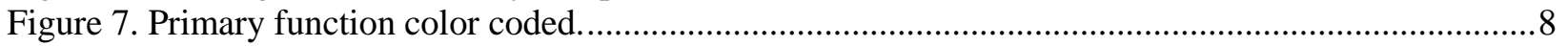

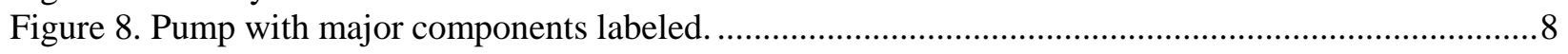

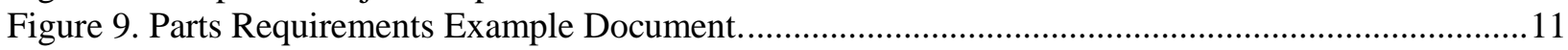

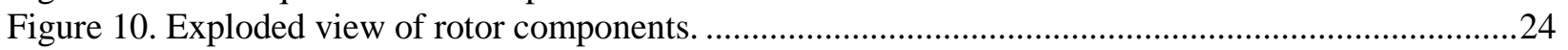

Figure 11. Exploded cross-section of stator assembly. ...................................................................25

Figure 12. Exploded cross-section view of pump module integration. ...................................................26

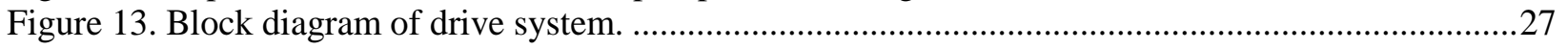

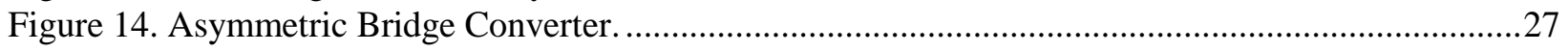

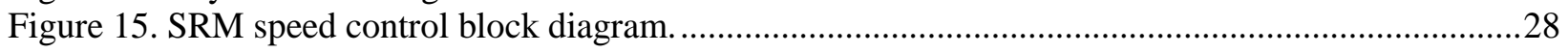

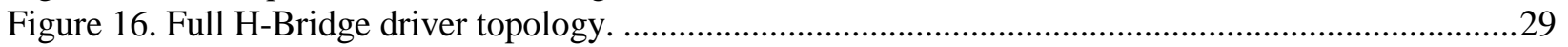





\section{LIST OF TABLES}

\section{Table}

Page

Table 1. Required Measurement Signals for Specific Motor System Component ....................................5

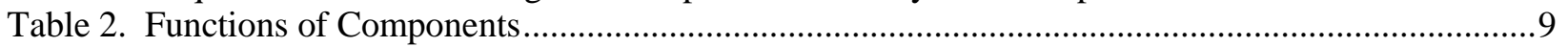

Table 3. Component Description and Material Options....................................................................... 13

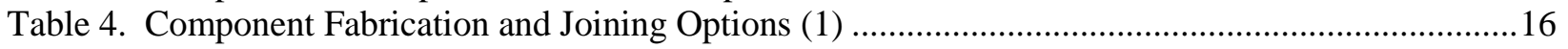

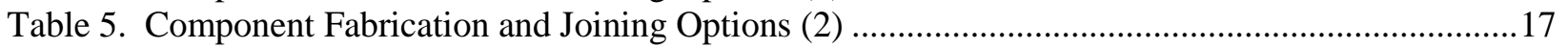

Table 6. Component Fabrication and Joining Options (3) .............................................................18

Table 7. Identified Component Issues - Design, Materials, Fabrication, or Joining (1).........................18

Table 8. Identified Component Issues - Design, Materials, Fabrication, or Joining (2) ..........................19 



\section{ACRONYMS}

$\begin{array}{ll}\text { A/D } & \text { analog to digital } \\ \text { ASI } & \text { Advanced Sensors and Instrumentation } \\ \text { BN } & \text { Boron Nitride } \\ \text { CTE } & \text { coefficient of thermal expansion } \\ \text { DOE } & \text { US Department of Energy } \\ \text { DOE-NE } & \text { US Department of Energy Office of Nuclear Energy } \\ \text { EDM } & \text { electrical discharge machining } \\ \text { FHR } & \text { fluoride-salt-cooled high-temperature reactor } \\ \text { I\&C } & \text { instrumentation and controls } \\ \text { ID } & \text { inner diameter } \\ \text { IGBT } & \text { insulated-gate bipolar transistor } \\ \text { NEET } & \text { Nuclear Energy Enabling Technologies } \\ \text { NPP } & \text { nuclear power plant } \\ \text { NRC } & \text { US Nuclear Regulatory Commission } \\ \text { OD } & \text { outer diameter } \\ \text { ORNL } & \text { Oak Ridge National Laboratory } \\ \text { PWM } & \text { pulse-width modulated } \\ \text { SiC } & \text { silicon carbide } \\ \text { SRM } & \text { switched reluctance motor } \\ \text { SS } & \text { stainless steel } \\ \text { SSC } & \text { systems, structures, and components }\end{array}$




\begin{abstract}
This report documents the current status of fabrication and assembly planning for the magnetic bearing, canned rotor pump being used as a demonstration platform for deeply integrating instrumentation and control (I\&C) into nuclear power plant components. The report identifies material choices and fabrication sequences for all of the required parts and the issues that need to be either resolved or accommodated during the manufacturing process. Down selection between material options has not yet been performed. Potential suppliers for all of the necessary materials have also been identified. The assembly evaluation begins by logically subdividing the pump into modules, which are themselves decomposed into individual parts. Potential materials and fabrication processes for each part in turn are then evaluated. The evaluation process includes assessment of the environmental compatibility requirements and the tolerances available for the selected fabrication processes. A description of the pump power/control electronics is also provided. The report also includes exploded views of the modules that show the integration of the various parts into modules that are then assembled to form the pump. Emphasis has been placed on thermal environment compatibility and the part dimensional changes during heat-up. No insurmountable fabrication or assembly challenges have been identified.
\end{abstract}

\title{
1. INTRODUCTION
}

The objective of this report is to document the assessment of the manufacturability of a conceptual design of a highly instrumented canned rotor, magnetic bearing, and reactor coolant pump. This report describes an assessment of materials, manufacturing methods, and design considerations for the conceptual design. The conceptual design was described in a previous report. ${ }^{1}$

Embedding sensors and controls deeply within the systems, structures, and components (SSC) of nuclear power plants (NPPs) has the potential to achieve otherwise unattainable improvements in performance, reliability, and reduced maintenance cost. The innovative approach of integrating instrumentation and control (I\&C) design into the system engineering process allows more advanced control systems that provide greater performance and robustness. High-temperature pumps represent a particularly suitable target demonstration due to their large potential for performance and reliability improvement and their widespread usage in advanced NPPs. The high-temperature, canned-rotor coolant pump is applicable to many of the Gen IV reactor types. Advanced embedded I\&C can increase coolant pump reliability and reduce their operating costs through a reduction in the maintenance burden on the plant by avoiding rotating seals and mechanical bearings. The practical objective of this project is to develop and demonstrate sensors and controls that operate as embedded parts of a high-temperature, canned-rotor coolant pump with magnetic bearings. This demonstration offers to the nuclear industry a concrete example to lead them into future design and deployment of components with embedded sensors and controls as a part of their functionality.

The high-temperature, harsh environments of advanced reactors - gas, liquid metal, and liquid-saltcooled provide a challenging environment for sensor design, and the increased noise and uncertainty in the measurements necessary for feedback control mean that traditional control techniques do not provide sufficient performance and stability for these highly complex multidisciplinary integrated systems. The new sensor techniques and the need to eliminate rotating seals and mechanical bearings necessitates the implementation of advanced control techniques capable of stabilizing the system and maintaining the performance requirements and physical bounds necessary for safe long-term operation in spite of the inherent sensor uncertainties. 
This report describes an assessment of materials, manufacturing methods, and design considerations for the conceptual design. This assessment will provide an indication of the challenges and risks of the conceptual design. The project is sponsored by the United States Department of Energy (DOE) Nuclear Energy Enabling Technologies (NEET) program whose mission is to develop crosscutting technologies that directly support and complement the Office of Nuclear Energy's (NE) development of new and advanced reactor concepts and fuel cycle technologies.

\subsection{OBJECTIVE}

The practical objective of this work is to tackle a difficult harsh environment problem common to many advanced power reactor designs by developing and demonstrating sensors and controls that operate as embedded parts of a system. The embedding concept allows deployment of reliable, highperformance plant components that otherwise would not be possible. Historically, coolant pumps for liquid metals, molten salts, and helium have been a limitation to achieving high plant reliability and are an ongoing maintenance burden. Conceptually, the fundamental mechanisms of any pump system are independent of the fluid being pumped; hence, the technologies developed for any modern hightemperature-tolerant pump system will crosscut several reactor classes. The helium circulator employed in the Next Generation Nuclear Plant Program, the sodium and liquid salt pumps employed by the Advanced Reactor Concepts program, as well as the Small Modular Reactors program would all benefit from this integrated sensing and controls demonstration project.

A specific motor-pump combination has been long pursued for harsh environmental applications-a high-temperature, magnetic bearing, canned-rotor pump. This system has been chosen as the I\&C demonstration platform for this project. The project is organized to demonstrate how modern I\&C technologies, such as fault tolerant computing, environmentally tolerant sensors, on-line diagnostics and prognostics, and integrated digital controls, can unite to improve NPP SSC.

To be successful, the process of designing a component possessing the embedded sensors and controls property must integrate the aspects of mechanical structure, magnetic effects, electrical characteristics, materials properties, thermal management, sensors, control algorithms, and electronics. The specific objective of the fabrication and assembly task is to examine and evaluate the important motor specific subcomponents and outline potential manufacturing and assembly options with a focus on system integration.

A pump for liquid-salt reactors was chosen as the specific pump system for the demonstration platform. The pump conceptual design includes material selection related to the application such as fluid wetted material compatibility for a liquid-fluoride-salt environment and high temperatures. Essentially the same materials are anticipated to be compatible with liquid sodium. The technology, in general, would also be applicable to pumping liquid lead if lead-compatible materials can be developed. Both the canned-rotor and magnetic-bearing aspects of the pump are also applicable to a helium or carbon dioxide compressor. The impellor blade configuration and rotational speed, however, would be significantly different for a gas coolant system. As a high-efficiency pump, a canned-rotor, magnetic-bearing design would be especially useful for sodium-cooled reactors because the induction pumps currently used have low efficiency (as low as 10 percent) ${ }^{2}$ compared with centrifugal pumps (at over 85 percent). In addition, induction pumps shut off abruptly (with no coast down) in the event of a loss-of-power accident. Further, vertical shaft pumps where the motor is outside of the liquid have the potential under accident conditions to entrain gas into the pumped fluid and can thus potentially provide a positive reactivity insertion into the core. 


\subsection{PUMP CONCEPT OVERVIEW}

The design intent of this project is to show that advanced embedded control and sensors can enable high-performance, high-reliability nuclear systems. The physical device being developed is a horizontal shaft, single-stage, centrifugal, high-temperature liquid pump that is compatible with liquid fluoride salts and temperatures as high as $700{ }^{\circ} \mathrm{C}$ (illustrated in Figure 1with annotations). The pump will feature both a canned rotor and active magnetic bearings, which removes traditional seals and mechanical bearings. The elimination of rotating seals and mechanical bearings provide enormous advantages in reduced maintenance requirements and the associated costs and downtime. In a canned rotor pump, the rotor of the pump motor is located entirely within the liquid. Thin-walled containers separate both the rotor and stator from the reactor coolant fluid. All of the stator windings are isolated from the fluid by the stator-can. The stator- and rotor-can features are illustrated in Figure 2 and Figure 3 . The addition of the canned rotor and stator eliminate any options to perform direct mechanical or optical sensory measurements on the rotor.

The rotor, in a magnetic bearing pump, is prevented from mechanically contacting the container by actively controlled magnetic levitation. A good general overview of magnetic bearings is available in "Magnetic Bearings and Bearingless Drives" by Chiba et al. ${ }^{3}$ Magnetic bearings are inherently unstable, which requires active feedback control to provide stability. The active control of the magnetic bearings requires feedback measurements of shaft position.

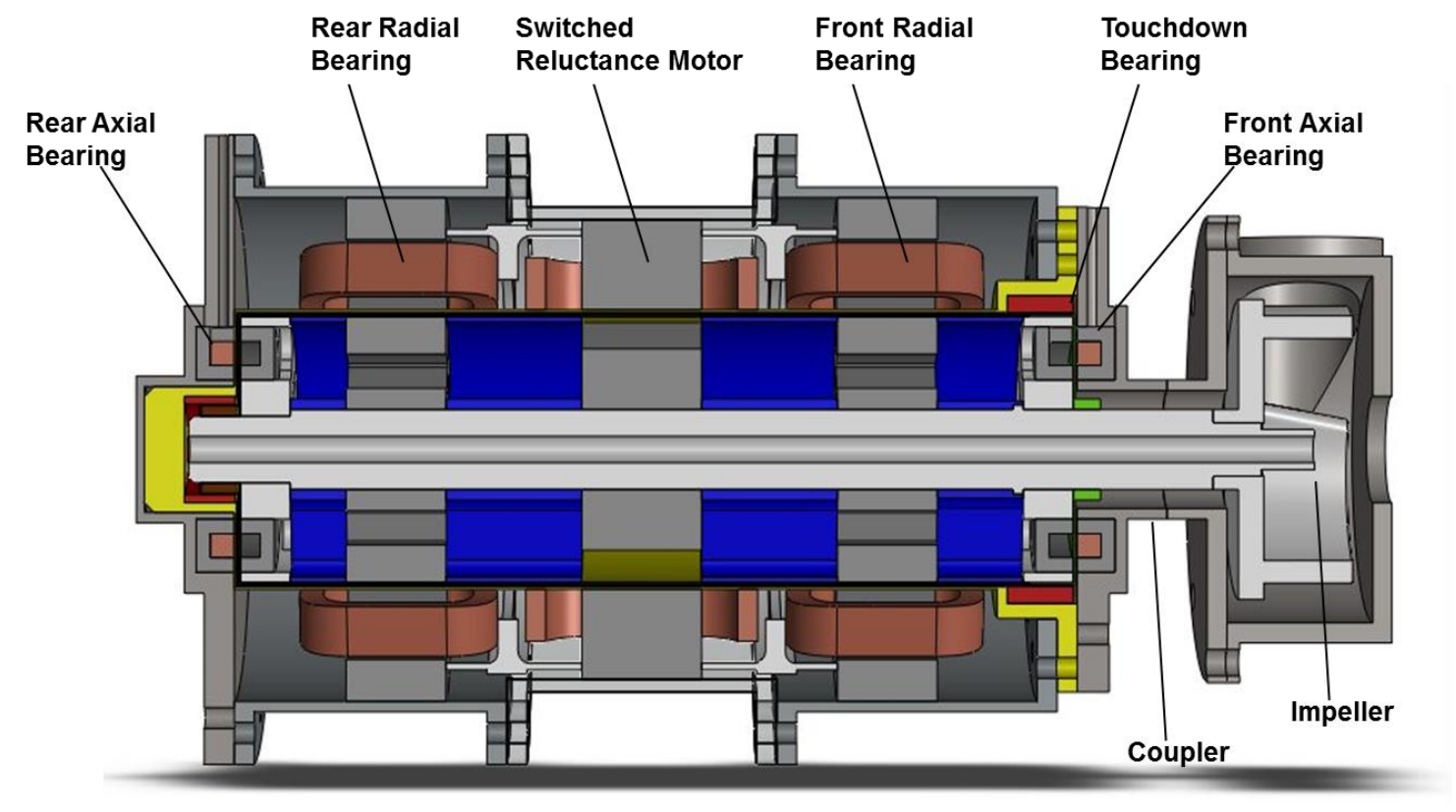

Figure 1. Reference illustration of canned rotor motor with pump impeller. 


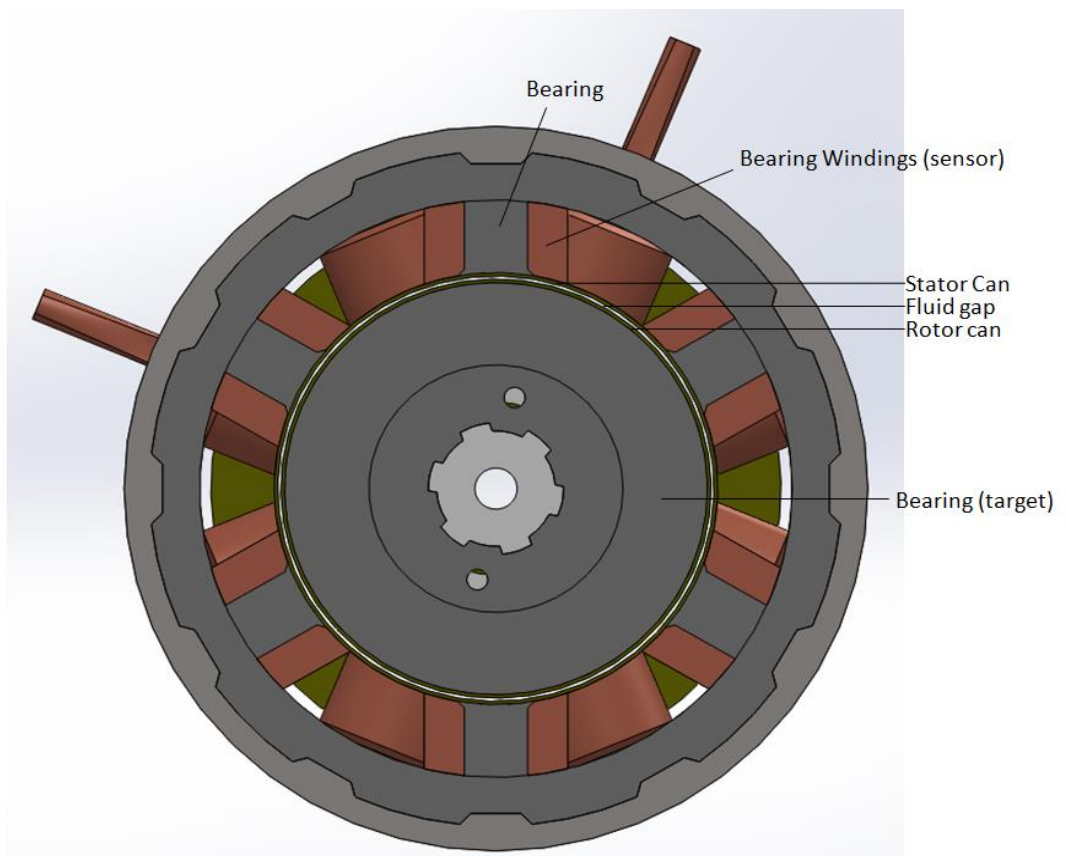

Figure 2. Cross section of motor bearing showing gap location.

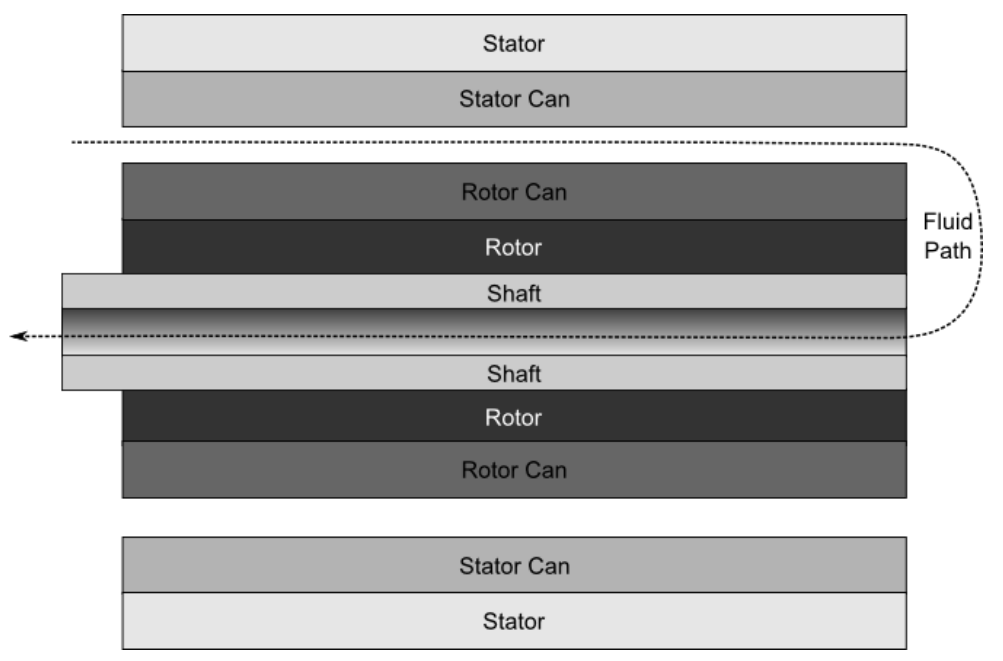

Figure 3. Illustration of materials stack in motor (not to scale).

The pump motor will employ a switched reluctance-type magnetic drive. A switched reluctance motor does not utilize permanent magnets that suffer from reduced magnetism at elevated temperatures. The switched reluctance motor, while being the most simple electro-mechanical motor design, is the most complex to control and requires high-fidelity position and rotational velocity measurements, which are challenging with the canned rotor configuration. The control of switched 
reluctance motors is more intimately coupled to the machine design than in other motors. A good overview of the design principles for switched reluctance motors is available in Praveen Vijayraghavan's 2001 dissertation "Design of Switched Reluctance Motors and Development of a Universal Controller for Switched Reluctance and Permanent Magnet Brushless Direct Current (DC) Motor Drives". A six-stator-pole, four-rotor-pole configuration has been selected as the initial design candidate.

The control of the pump magnetic bearings and motor require various measurements as shown in Table 1. The high operating temperatures and the canned rotor construction prevent direct measurement of the rotor rotational position and speed. There are two general approaches to implementing the various measurements: (1) independent sensors and (2) sensorless. Our strategy is to employ both approaches to provide redundancy and self-checking ability. Independent sensors are realized by measurements taken by transduction separate from the current-driven windings for magnetic suspension or the main rotation drive. A rotation and translational resolver concept for hightemperature operation is in consideration as an independent sensor for shaft rotation angle, shaft speed, and shaft bearing position measurements. Note that the motor cross sections are shown in this report without the independent sensor components. Sensorless position estimation is often carried out with flux linkage estimation from on-cycle operation and it is possible to monitor voltages on stator windings during the off cycle.

Table 1. Required Measurement Signals for Specific Motor System Component

\begin{tabular}{lccccc}
\hline \multirow{2}{*}{\multicolumn{1}{c}{ Measurement }} & \multicolumn{5}{c}{ Component } \\
\cline { 2 - 6 } & Thrust 1 & Thrust 2 & Bearing 1 & Bearing 2 & Torque \\
\hline $\mathrm{X}_{1}$ Position & $\mathrm{X}$ & $\mathrm{X}$ & $\mathrm{X}$ & $\mathrm{X}$ & \\
$\mathrm{X}_{2}$ Position & $\mathrm{X}$ & $\mathrm{X}$ & $\mathrm{X}$ & $\mathrm{X}$ & \\
$\mathrm{Y}_{1}$ Position & $\mathrm{X}$ & $\mathrm{X}$ & $\mathrm{X}$ & $\mathrm{X}$ & \\
Y $_{2}$ Position & $\mathrm{X}$ & $\mathrm{X}$ & $\mathrm{X}$ & $\mathrm{X}$ & \\
Z Position & $\mathrm{X}$ & $\mathrm{X}$ & & & \\
Angular Position & & & & & $\mathrm{X}$ \\
Stator Temperature & $\mathrm{X}$ & & $\mathrm{X}$ & $\mathrm{X}$ & $\mathrm{X}$ \\
Current & $\mathrm{X}$ & & $\mathrm{X}$ & $\mathrm{X}$ & $\mathrm{X}$ \\
Voltage & $\mathrm{X}$ & & $\mathrm{X}$ & $\mathrm{X}$ & $\mathrm{X}$ \\
\hline
\end{tabular}

A simplified block diagram of the motor and bearing control system is given in Figure 4. The diagram illustrates the measured values coming from sensors or stator windings and output currents, and signals going to various stator windings. Command signals and status parameters are communicated to higher levels of the control hierarchy. The internal functions of the control system can be summarized as the blocks indicate-input electronics [e.g., input protection, analog-todigital (A/D) conversion], signal processing (e.g., filtering, estimation, and model prediction), control calculations (for magnetic suspension, main rotational drive, and temperature control), diagnostics/prognostics, high-frequency current drive, and external communications. 


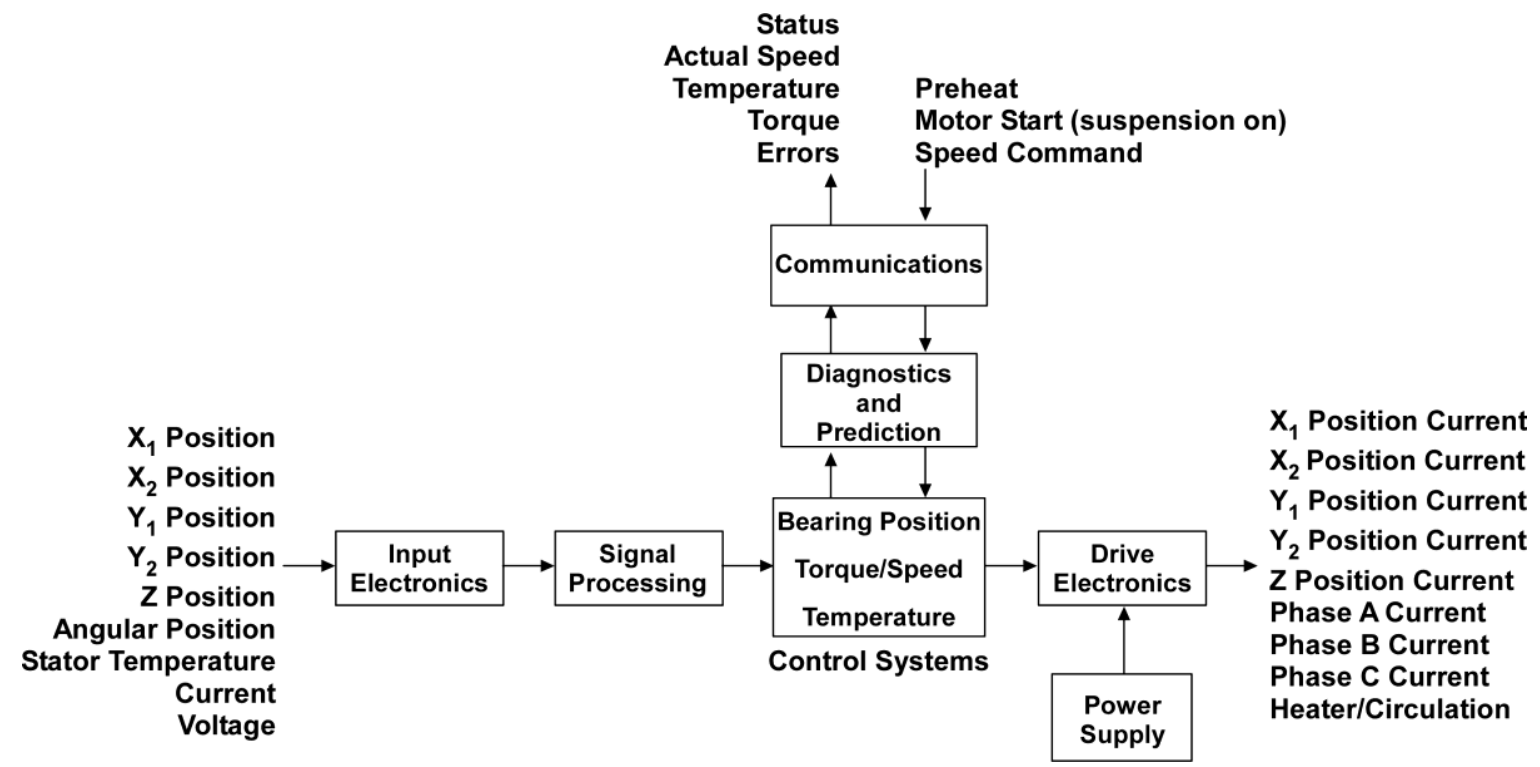

Figure 4. Simplified system control electronics block diagram. 


\section{PUMP CONCEPTUAL DESIGN}

The pump conceptual design consists of multiple functions of components, the desired levels of functionality, embedded sensing, embedded control, and the harsh environmental conditions requires thoughtful integration of the components. These components can be organized using various approaches such as location, function, or other criteria.

For the conceptual design, components are organized by major sub-system groups such as the rotor, stator, coupler, and end cap as shown in Figure 5. The outcome is that components such as rotor components are designated rotor R-01, R-02, etc. Figure 6 illustrates the rotating versus stationary components. The rotor contains mechanical and magnetic components and the stator contains mechanical, electrical, and magnetic components. Figure 7 illustrates the primary function of components with a color code scheme.

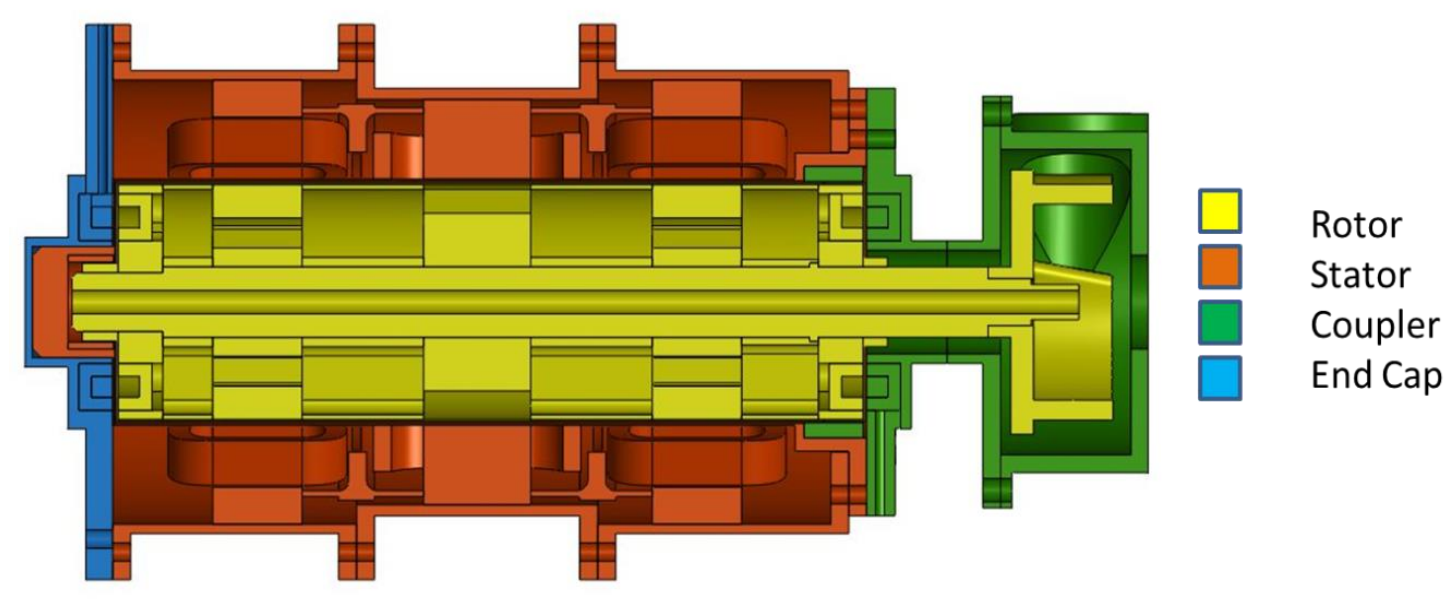

Figure 5. Major component groups (rotor, stator, coupler, and end cap) color coded.

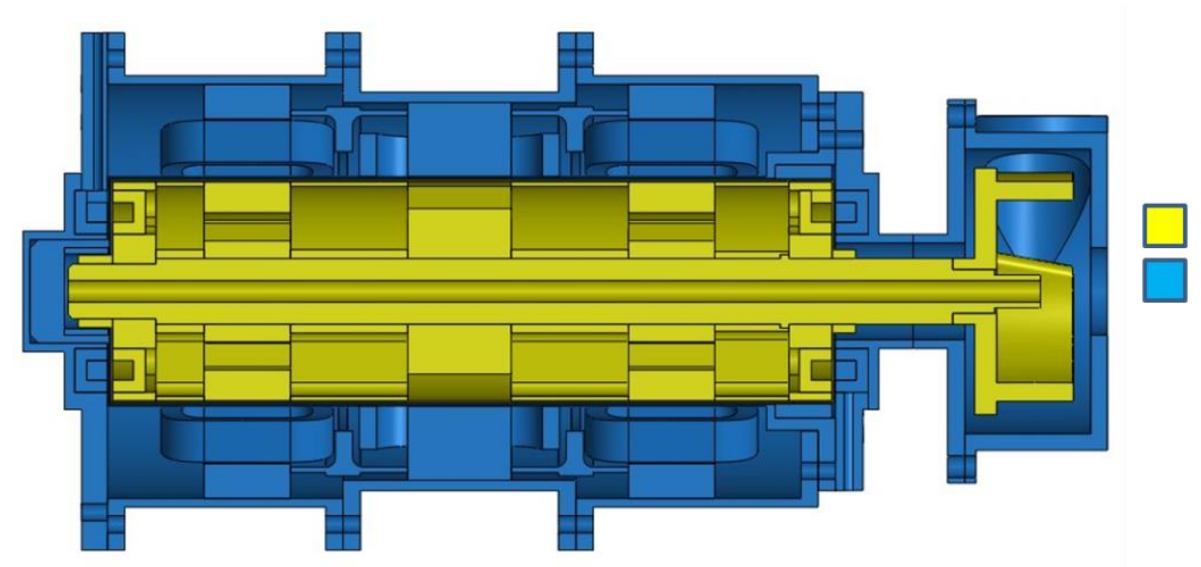

Rotating

Stationary

Figure 6. Rotating versus stationary components color coded. 


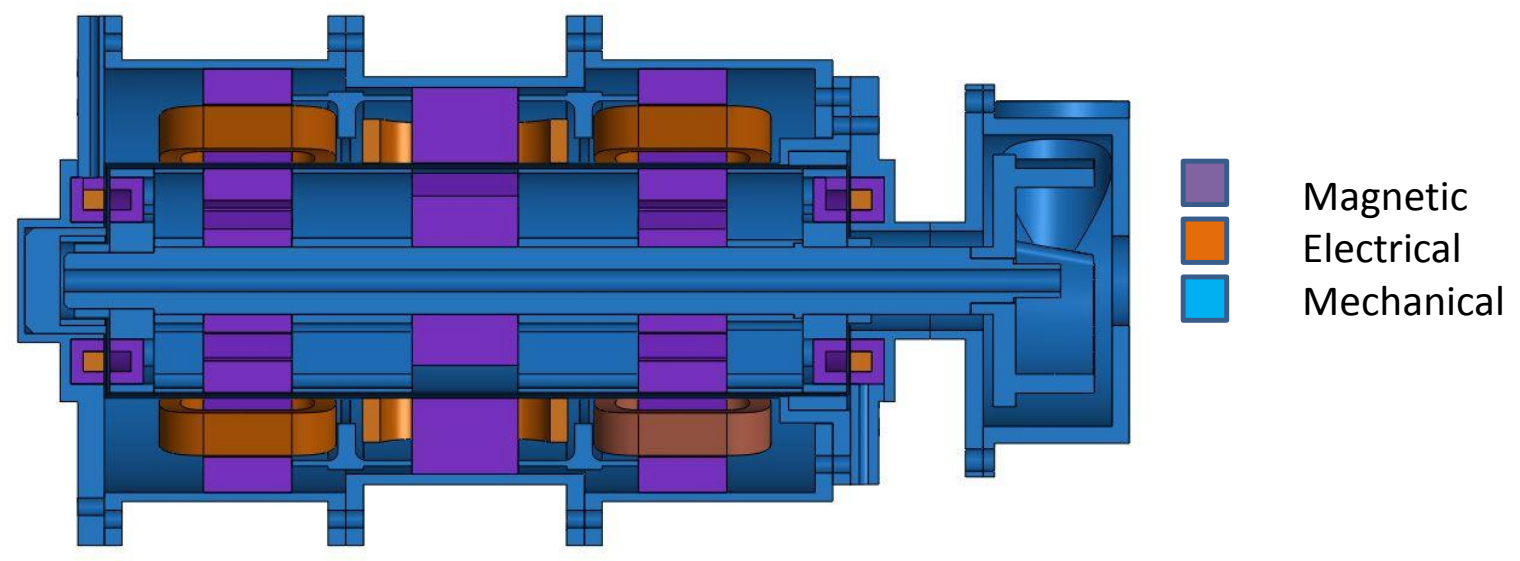

Figure 7. Primary function color coded.

The locations of all major components in the motor-pump electro-mechanical system are shown diagrammatically in Figure 8. The primary and secondary functions of each component have been identified (see Table 2). In the embedded design process, complex designs are matured through an iterative process of design and analysis steps. Various studies and analyses of the conceptual design are in progress and are discussed in Section 3 of the report.

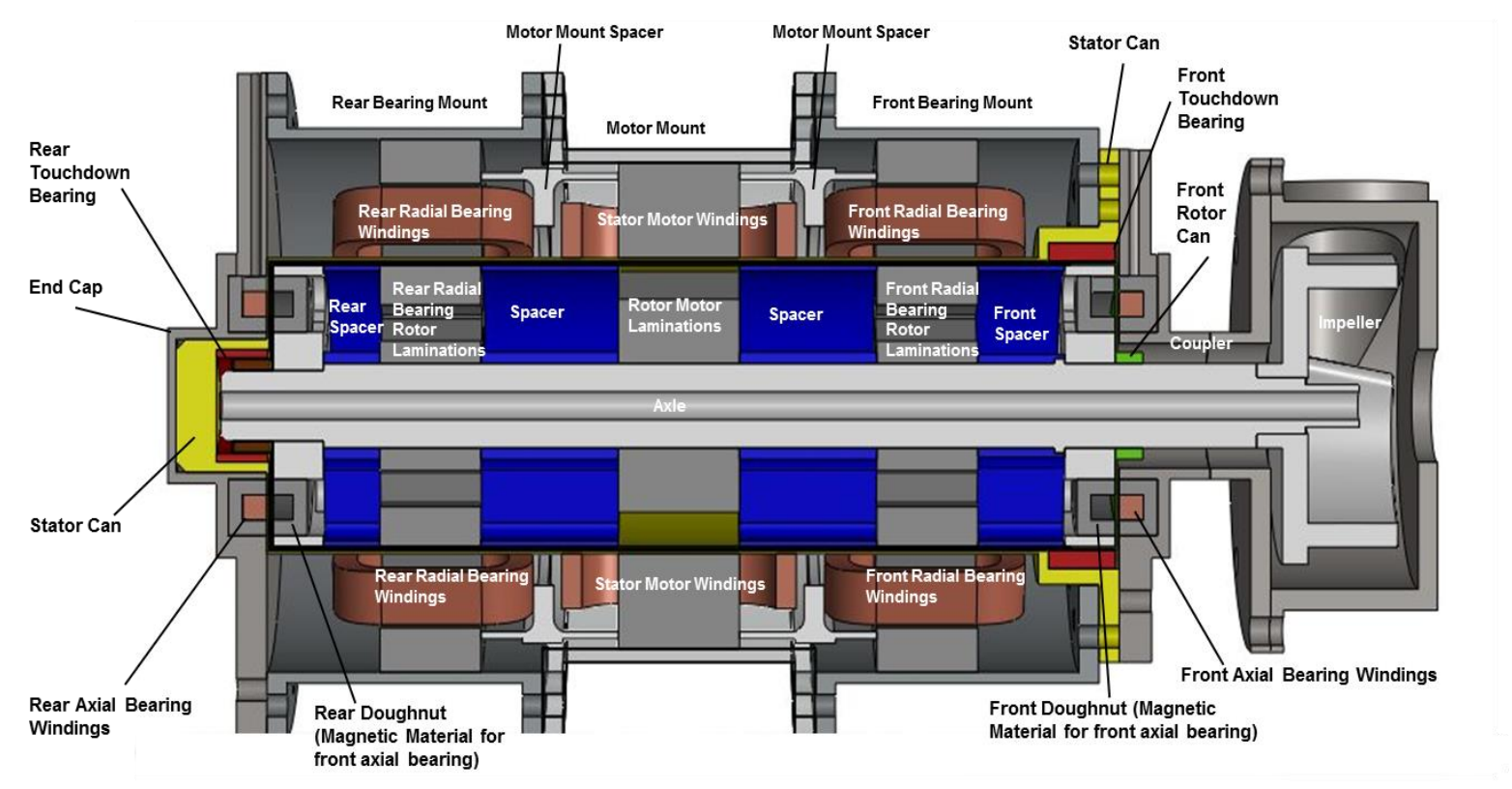

Figure 8. Pump with major components labeled. 
Table 2. Functions of Components

\begin{tabular}{|c|c|c|c|}
\hline Components & Rotor & Primary Function & Secondary Function \\
\hline Axle & 1 & mechanical & mechanical \\
\hline Impeller & 2 & mechanical & mechanical \\
\hline Rotor Can Front & 3 & mechanical & mechanical \\
\hline \multirow{2}{*}{ Front Axial Bearing Mount } & \multirow{2}{*}{4} & mechanical & \multirow{2}{*}{ mechanical } \\
\hline & & magnetic & \\
\hline Front Spacer & 5 & mechanical & \\
\hline Bearing Rotor (Front \& Back) & 6 & mechanical & sensing \\
\hline Spacer (Middle Front \& Middle Back) & 7 & mechanical & \\
\hline \multirow{2}{*}{ Rotor Motoring Laminations } & \multirow{2}{*}{8} & \multirow{2}{*}{ magnetic } & mechanical \\
\hline & & & sensing \\
\hline Rear Spacer & 9 & mechanical & \\
\hline \multirow{2}{*}{ Rear Axial Bearing Mount } & \multirow{2}{*}{10} & mechanical & \multirow{2}{*}{ mechanical } \\
\hline & & magnetic & \\
\hline Rotor Can Rear & 11 & mechanical & mechanical \\
\hline \multicolumn{4}{|c|}{ Coupler } \\
\hline Coupler & 1 & mechanical & sensing \\
\hline Front Axial Bearing Windings & 2 & magnetic & electrical \\
\hline Touchdown Front & 3 & mechanical & mechanical \\
\hline
\end{tabular}

\begin{tabular}{|c|c|c|c|}
\hline \multicolumn{4}{|c|}{ Stator } \\
\hline Stator Can & 1 & mechanical & mechanical \\
\hline Touchdown Rear & 2 & mechanical & mechanical \\
\hline Rear Bearing Mount & 3 & mechanical & sensing \\
\hline Rear Bearing & 4 & magnetic & electrical \\
\hline Motor Mount & 5 & mechanical & sensing \\
\hline \multirow{2}{*}{ Stator Windings } & \multirow{2}{*}{6} & \multirow{2}{*}{ magnetic } & electrical \\
\hline & & & sensing \\
\hline Front Bearing Mount & 7 & mechanical & sensing \\
\hline Front Bearing & 8 & magnetic & electrical \\
\hline
\end{tabular}

Methods for capturing and managing the design details of each component and their interfaces with other components were investigated. Surprisingly, few commercial tools exist to perform this analysis for multiple components over a range of design considerations such as thermal expansion, mechanical tolerances, loads, and forces. Instead, many industries use internally developed tools that are considered proprietary. Therefore, some tools have been developed in the course of this assessment task to manage and document design details and component interfaces in a manner that allows design evaluation.

The conceptual design was analyzed to develop initial engineering drawings with appropriate dimensions and tolerances (Appendix A.1). The initial dimensions and tolerances will be used to study tolerance interactions and thermal expansion considerations, and form a basis for understanding the critical considerations for component fabrication and assembly.

Parts requirement documents were developed to capture design details, considerations, and interactions for each component with an example shown in Figure 9. The document captures various fields of information for each part. The choice of Alloy $\mathrm{N}$ is a preferred material because it is with functional at temperature and compatible with fluoride salt. The parts requirement documents (see Appendix A.2) include the following information categories: 
1. Part Name, Module Designator - Part naming and designation

2. Location - Location on assembly

3. Description - Component description.

4. Primary \& Secondary Function - Description of various functions of a component.

5. Operating Conditions - Description of conditions such as temperature, dynamics, speeds, and fluoride salt exposure.

6. Load Sources and Requirements - Description of the source and type of mechanical force loading.

7. Lead and alternate materials

8. Material considerations - Special notes about materials considerations.

9. Fabrication methods - Suggested methods for manufacturing fabrications.

10. Attached to - Component interaction.

11. Joining options - Suggested methods for joining or attachment.

12. Dimensional specifications - Notes and reference to engineering drawing.

13. Design and Fabrication Issues - Notes about issues for consideration.

14. Failure Modes - Notes about key failure modes to consider.

15. Other

The parts requirement documents for all components are located in Appendix A.2. This information will be used as an input for design evaluation and improvement activities documented in this report. 
Part Name, Module Designation: Axle, Rotor, R-01-V0.0

Location: Center of Rotor

Description: Shaft of Rotor

Primary Function: Mechanical transfer of torque from laminations to impeller rotation

Secondary Function: Mechanical attachment for impeller, bearings, motor laminations, rotor spacers, each end of rotor can, and fluid control

Operating Conditions

\begin{tabular}{l|l|}
\hline Temperature & $650-700 \mathrm{C}$ \\
\hline Component dynamics & Rotational \\
\hline Speed & 3600 RPM \\
\hline Exposed to salt? & YES \\
\hline
\end{tabular}

Load Sources and Requirements: The primary loads on the axle arise from rotor dynamic forces. The axle stiffness needs to be designed such that the maximum axial rotor dynamic forces seen during spin-up and normal operation don't cause rubbing between the rotor and stator. The impeller forces will also be transferred to the axle, specifically, radial forces due to the suction head at the impeller inlet, and torque pulses at the impeller output due to the discrete number of blades.

Lead and alternate materials: Alloy $\mathrm{N}\left(\mathrm{Hastelloy}^{\circledR} \mathrm{N}\right.$ ) / $316 \mathrm{SS} / 800 \mathrm{H} /$ Alloy 600/ Alloy 617

Material Considerations: Parts of the axle will be exposed to the corrosive effects of the molten salt so the axle material must withstand these effects for the lifetime of the part without affecting the part functionality.

Fabrication methods: Machining \& Grinding (Spline End may require EDM or Water Jet). The axle will be machined from bar stock. Splines will be rough ground into the axle and the axle will be heat treated afterwards to relieve grinding stress, the final grinding will be performed.

Axle balance is critical so the axle will be balanced radially.

Attached to: Base Piece

Joining options: Base Piece

Dimensional specifications (finish/tolerance): refer to Appendix A.1.1

Design \& Fabrication Issues: Material Availability, Assembly Sequence \& Distortion

Failure Modes: Chemical erosion, vibration (creep, fatigue), rubbing, salt interjection between axle and laminations, weld failure.

Other:

Suggestion: Concern about transition at end of spline for a square contour. Extend spline to face or rotor can front and use a grove/snap ring or pin to locate rotor can front for welding processes.

Figure 9. Parts Requirements Example Document. 


\section{FABRICATION AND ASSEMBLY ASSESSMENT}

As part of the process to mature the conceptual design into a candidate for prototyping, various types of analysis and reviews are required to determine the viability of the conceptual design and to determine various design details. This section focuses on assessing the manufacturability of the pump hardware and identifying design and manufacturability concerns. The section is organized by (1) materials, (2) fabrication, and (3) assembly. Design discussions and reviews are focused on selection of materials, various functions and purposes of the design components, and identification of candidate fabrication and assembly methods.

\subsection{MATERIALS}

Selection of primary and alternate materials for each component included a number of considerations including the maximum operational temperature, exposure to fluoride salt, the component characteristics and its mechanical, magnetic, and electrical properties. Materials investigations and research have identified a number of candidate materials. Candidate materials are also evaluated for manufacturing characteristics. Table 3 provides descriptions of each component as well as material options to consider. Preferred material option is listed first in the materials column. The key materials of interest are summarized below with additional properties listed in Appendix A.2.

1. Alloy N: Alloy N (UNS 10003), also known as Hastelloy ${ }^{\circledR} \mathrm{N}$, is a nickel-based alloy that has good resistance to oxidation in high-temperature environments. Hastelloy ${ }^{\circledR} \mathrm{N}$ is an alloy that was designed to balance resistance to liquid fluoride salt corrosion while exhibiting good creep properties at temperatures up to $704{ }^{\circ} \mathrm{C}$. Above $704{ }^{\circ} \mathrm{C}$, the creep strength decreases rapidly. Alloy $\mathrm{N}$ can resist oxidation in a temperature range from $704^{\circ} \mathrm{C}$ to $871^{\circ} \mathrm{C}$. It also has good weldability, and shows no tendency towards embrittlement. During forming operations, this material work-hardens very rapidly. Alloy $\mathrm{N}$ is available from Haynes International.

2. Alloy 600: Alloy 600 (UNS N06600) is a nickel-chromium non-magnetic alloy that has high strength and good resistance to oxidation and corrosion at high temperatures. Its corrosion resistance to liquid fluoride salt is less than that of Alloy N. It can resist many acid salts, and has good strength and workability under temperatures that range from cryogenic up to over $1095^{\circ} \mathrm{C}$. It is used in nuclear engineering applications. Alloy 600 is available from multiple vendors.

3. Alloy 617: Alloy 617 (UNS N06617) is a nickel-chromium-cobalt molybdenum alloy that has high-temperature strength and resistance to corrosive aqueous environments. It has oxidation resistance at temperatures over $980^{\circ} \mathrm{C}$. Its corrosion resistance to liquid fluoride salt is less than that of Alloy N. Alloy 617 is available from multiple vendors.

4. Alloy 800H: Alloy $800 \mathrm{H}$ (UNS N08811) is an iron-nickel-chromium alloy with excellent resistance to oxidation and carburization in high-temperature environments. It also has good resistance to corrosion in different environments. It is mainly used in high temperature applications such as industrial furnaces, valves, fittings, and applications involving corrosive environments. Its corrosion resistance to liquid fluoride salt is less than that of Alloy N. Alloy $800 \mathrm{H}$ is available from multiple vendors.

5. Iron Cobalt Vanadium Alloy: Iron-cobalt-vanadium soft magnetic alloy possesses the highest magnetic saturation of any alloy, up to 24 kilogauss, and exhibits high permeability. Its magnetic transition temperature is $980^{\circ} \mathrm{C}$. Iron-cobalt-vanadium soft magnetic alloy is the preferred material for rotor and stator laminations in motors and generators, magnetic 
bearings, and poles for electromagnets. Both Carpenter Technology and Vacuumschmelze sell iron cobalt alloys.

6. Silicon Carbide: $\mathrm{SiC}$ is a ceramic material. It is available from multiple suppliers with differing binder phases and stoichiometry. For salt wetted applications, it is important to avoid compositions containing oxide binder phases or free silicon because fluoride salts will rapidly dissolve the material. Stoichiometric $\mathrm{SiC}$ has strength retention at high temperatures and is resistant to acids and molten salts up to temperatures of $800^{\circ} \mathrm{C}$. This material has a high thermal conductivity. Typical uses of silicon carbide include fabrication of seals and bearings. This material has very little ductility. Saint Gobain sells industrial grade silicon carbide shapes.

7. Boron Nitride: BN, a chemical compound consisting of an equal amount of boron and nitrogen atoms, is a synthetic material that has high electrical resistance, and a low dielectric constant. Boron Nitride has a high thermal conductivity and good thermal shock resistance. It is also resistant to oxidation in air at temperatures up to $850^{\circ} \mathrm{C}$. Boron nitride is used for fabrication of parts in high-temperature equipment, electronic parts, low-friction seals, as an electrical insulator, and other applications. This material has very little ductility in solid form but is also available as a paste. Boron nitride is most commonly employed as 95 percent $\mathrm{BN}$, 5 percent $\mathrm{B}_{2} \mathrm{O}_{3}$. The paste variety has a carrier (e.g. water or alcohol) that must be evaporated during fabrication to prevent pressure buildup and distortion. Boron nitride coating is available from Zyp Coatings and other companies.

8. Glass Coated Wire: Glass coated copper wire is a high temperature tolerant electrical conductor for magnetic (and other) applications. The glass coating is multi-component oxide material. Suitable wire for the pump is available from GW Lab.

Table 3. Component Description and Material Options.

\begin{tabular}{|c|c|c|}
\hline Part & Description & Materials \\
\hline Axle & $\begin{array}{l}\text { The axle is the base of the } \\
\text { rotor. It is designed to support } \\
\text { and align the axial bearing } \\
\text { laminations, radial bearing and } \\
\text { rotor laminations, and } \\
\text { impeller. Transfers motor } \\
\text { torque to impeller. }\end{array}$ & $\begin{array}{l}\text { Hastelloy }{ }^{\circledR} \mathrm{N}, 316 \mathrm{SS}, 800 \mathrm{H} \text {, } \\
\text { Alloy } 617\end{array}$ \\
\hline Impeller & $\begin{array}{l}\text { The rotating impeller of this } \\
\text { centrifugal pump creates the } \\
\text { necessary pressure increase in } \\
\text { the incoming fluid. }\end{array}$ & Hastelloy $^{\circledR}$ N, 316 SS, $800 \mathrm{H}$ \\
\hline Coupler & $\begin{array}{l}\text { Joins impeller housing to } \\
\text { stator mount. Joins supporting } \\
\text { structure to front axial } \\
\text { bearing. }\end{array}$ & Hastelloy $^{\circledR}$ N, 316 SS, 800H \\
\hline
\end{tabular}




\begin{tabular}{|c|c|c|}
\hline Part & Description & Materials \\
\hline Front Axial Bearings & $\begin{array}{l}\text { Controls the axial position of } \\
\text { the rotor assembly. }\end{array}$ & Hastelloy ${ }^{\circledR}$ N, 316 SS, 800H \\
\hline Rotor-Can Front & $\begin{array}{l}\text { Front of motor barrier } \\
\text { between rotor and molten } \\
\text { salt. }\end{array}$ & Hastelloy ${ }^{\circledR}$ N, 316 SS, $800 \mathrm{H}$ \\
\hline $\begin{array}{l}\text { Front Touchdown } \\
\text { Bearing }\end{array}$ & $\begin{array}{l}\text { Radial touchdown bearing at } \\
\text { front of rotor. Absorbs impact } \\
\text { in case of bearing failure. }\end{array}$ & SiC, Graphite \\
\hline Stator-Can & $\begin{array}{l}\text { Structure that protects stator } \\
\text { from coming into contact with } \\
\text { molten salt. }\end{array}$ & Hastelloy ${ }^{\circledR}$ N, 316 SS, $800 \mathrm{H}$ \\
\hline $\begin{array}{c}\text { Front Axial Bearing } \\
\text { Mount }\end{array}$ & $\begin{array}{l}\text { Supports front axial bearing } \\
\text { magnetic material }\end{array}$ & Hastelloy ${ }^{\circledR} \mathrm{N}, 316 \mathrm{SS}, 800 \mathrm{H}$ \\
\hline Front Spacer & $\begin{array}{l}\text { Spacer between front radial } \\
\text { bearing and axial bearing. }\end{array}$ & Hastelloy ${ }^{\circledR} \mathrm{N}, 316 \mathrm{SS}, 800 \mathrm{H}$ \\
\hline $\begin{array}{l}\text { Rotor Bearing (front } \\
\text { and rear) }\end{array}$ & $\begin{array}{l}\text { Interacts with magnetic field in } \\
\text { order to modify radial rotor } \\
\text { position. }\end{array}$ & Iron Cobalt Alloy, BN Insulator \\
\hline Middle Front Spacer & $\begin{array}{l}\text { Spacer between front radial } \\
\text { bearing and rotor laminations. }\end{array}$ & Hastelloy ${ }^{\circledR} \mathrm{N}, 316 \mathrm{SS}, 800 \mathrm{H}$ \\
\hline Middle Rear Spacer & $\begin{array}{l}\text { Spacer between rotor } \\
\text { laminations. }\end{array}$ & Hastelloy ${ }^{\circledR} \mathrm{N}, 316 \mathrm{SS}, 800 \mathrm{H}$ \\
\hline Rotor Laminations & $\begin{array}{l}\text { Rotor laminations provide } \\
\text { torque driving the impeller by } \\
\text { aligning with magnetic field } \\
\text { produced by the stator } \\
\text { windings. }\end{array}$ & Iron Cobalt Alloy, BN Insulator \\
\hline Rear Spacer & $\begin{array}{l}\text { Spacer between rear radial } \\
\text { bearing relative to rotor. }\end{array}$ & Hastelloy ${ }^{\circledR} \mathrm{N}, 316 \mathrm{SS}, 800 \mathrm{H}$ \\
\hline $\begin{array}{c}\text { Rear Axial Bearing } \\
\text { Mount }\end{array}$ & $\begin{array}{l}\text { Supports rear axial bearing } \\
\text { magnetic material. }\end{array}$ & Hastelloy ${ }^{\circledR}$ N, 316 SS, $800 \mathrm{H}$ \\
\hline Rotor-Can Rear & $\begin{array}{l}\text { Rear of motor barrier between } \\
\text { rotor and molten salt. }\end{array}$ & Hastelloy ${ }^{\circledR} \mathrm{N}, 316 \mathrm{SS}, 800 \mathrm{H}$ \\
\hline $\begin{array}{l}\text { Rear Touchdown } \\
\text { Bearing }\end{array}$ & $\begin{array}{l}\text { Radial touchdown bearing at } \\
\text { rear of rotor. Absorbs impact } \\
\text { in case of bearing failure. }\end{array}$ & SiC, Graphite \\
\hline End Cap & Encloses rear section of rotor. & 316 SS \\
\hline Rear Axial Bearings & $\begin{array}{l}\text { Controls the axial position of } \\
\text { the rotor assembly. }\end{array}$ & Hastelloy ${ }^{\circledR}$ N, 316 SS, $800 \mathrm{H}$ \\
\hline Rear Bearing Mount & Encloses rear section of stator. & 316 SS \\
\hline
\end{tabular}




\begin{tabular}{|c|c|c|}
\hline Part & Description & Materials \\
\hline $\begin{array}{l}\text { Rear (radial) Bearing } \\
\text { (windings) }\end{array}$ & $\begin{array}{l}\text { Rear radial bearing windings. } \\
\text { Carries current that will } \\
\text { produce magnetic field for } \\
\text { radial positioning. }\end{array}$ & $\begin{array}{l}\text { Iron Cobalt Alloy, BN } \\
\text { Insulator, glass coated copper } \\
\text { wire }\end{array}$ \\
\hline Motor Mount & Middle stator enclosure. & 316 SS \\
\hline Stator Windings & $\begin{array}{l}\text { Stator motor windings. Carries } \\
\text { current that will produce } \\
\text { magnetic field for rotor } \\
\text { torque. }\end{array}$ & $\begin{array}{l}\text { Iron Cobalt Alloy, BN } \\
\text { Insulator, glass coated copper } \\
\text { wire }\end{array}$ \\
\hline Front Bearing Mount & Front stator enclosure. & 316 SS \\
\hline $\begin{array}{l}\text { Front (radial) Bearing } \\
\text { (windings) }\end{array}$ & $\begin{array}{l}\text { Front radial bearing windings. } \\
\text { Carries current that will } \\
\text { produce magnetic field for } \\
\text { radial positioning. }\end{array}$ & $\begin{array}{l}\text { Iron Cobalt Alloy, BN } \\
\text { Insulator, glass coated copper } \\
\text { wire }\end{array}$ \\
\hline Stator Laminations & $\begin{array}{l}\text { Concentrates/directs magnetic } \\
\text { field and Incorporates the } \\
\text { stator windings that produces } \\
\text { the necessary magnetic field } \\
\text { for torque production. }\end{array}$ & $\begin{array}{l}\text { Iron Cobalt Alloy, BN } \\
\text { Insulator, glass coated copper } \\
\text { wire }\end{array}$ \\
\hline $\begin{array}{l}\text { Outer Bearing } \\
\text { Laminations }\end{array}$ & $\begin{array}{l}\text { Incorporates the bearing } \\
\text { windings that produce the } \\
\text { necessary magnetic field for } \\
\text { position control. }\end{array}$ & Iron Cobalt Alloy \\
\hline
\end{tabular}

\subsection{FABRICATION}

The assessment of fabrication methods for each component necessitates understanding the requirements, materials, dimensions, tolerances, and the capabilities of various fabrication methods. As part of this assessment, candidate fabrication methods were identified for investigation. Attachment, assembly, and joining techniques and procedures for various components are not inconsequential with the consideration of the environmental conditions and the nature and function of the components. Components must be assembled in temperatures much lower than the target operating temperature. The joining technique must be compatible with these large temperature differences. Table 4, Table 5, and Table 6 summarize the candidate fabrication and assembly methods for each component. Issues and concerns are identified in Table 7 and Table 8 . This information will be utilized during design review activities to determine the feasibility for each component design. 
Table 4. Component Fabrication and Joining Options (1)

\begin{tabular}{|c|c|c|c|}
\hline Part & $\begin{array}{c}\text { Module } \\
\text { Designation }\end{array}$ & Fabrication Methods & Joining Options \\
\hline Axle & $\mathrm{R}-01$ & $\begin{array}{c}\text { Machining } \\
\text { Grinding } \\
\text { Machined from bar stock } \\
\text { Splines rough ground into axle. (Spline end } \\
\text { might require EDM or Water Jet) } \\
\text { Heat treatment of axle afterwards } \\
\text { Final grinding of part } \\
\end{array}$ & Base piece \\
\hline Impeller & R-02 & $\begin{array}{c}\text { Machining } \\
\text { Grinding (thread impeller or use fastening nut) }\end{array}$ & $\begin{array}{l}\text { Joined to Axle Impeller } \\
\text { end by internal threads, } \\
\text { or } \\
\text { Joined to Axle by spline } \\
\text { fit and nut } \\
\end{array}$ \\
\hline $\begin{array}{l}\text { Front Rotor- } \\
\quad \text { Can }\end{array}$ & R-03 & Sheet rolled (hydroform) Welding & $\begin{array}{l}\text { Joined to axle with } \\
\text { circular weld (or } \\
\text { vacuum braze } \\
\text { gold/nickel) } \\
\text { Joined to rear rotor-can } \\
\text { with circular weld and } \\
\text { grind }\end{array}$ \\
\hline $\begin{array}{c}\text { Front Axial } \\
\text { Bearing Mount }\end{array}$ & $\mathrm{R}-04$ & $\begin{array}{l}\text { Machining } \\
\text { Grinding }\end{array}$ & $\begin{array}{l}\text { Attached to axle with } \\
\text { vacuum braze } \\
\text { Floating without } \\
\text { attachment } \\
\end{array}$ \\
\hline Front Spacer & R-05 & $\begin{array}{c}\text { Machining } \\
\text { Grinding } \\
\end{array}$ & $\begin{array}{l}\text { Attached to Axle } \\
\text { Floating }\end{array}$ \\
\hline Bearing Rotor & R-06 & $\begin{array}{l}\text { Standard lamination practices (pin and press } \\
\text { lamination sheets into one assembly and add } \\
\text { insulator) } \\
\text { Assembly is splined to axle }\end{array}$ & $\begin{array}{l}\text { Attached to Axle } \\
\text { Floating }\end{array}$ \\
\hline $\begin{array}{l}\text { Middle Front } \\
\text { and Middle } \\
\text { Rear Spacer }\end{array}$ & R-07 & $\begin{array}{l}\text { Machining } \\
\text { Grinding }\end{array}$ & $\begin{array}{l}\text { Attached to Axle } \\
\text { Floating }\end{array}$ \\
\hline $\begin{array}{c}\text { Rotor } \\
\text { Laminations }\end{array}$ & R-08 & $\begin{array}{l}\text { Standard lamination practices (pin and press } \\
\text { lamination sheets into one assembly and add } \\
\text { insulator) } \\
\text { Assembly is splined to axle }\end{array}$ & $\begin{array}{l}\text { Attached to Axle } \\
\text { Floating }\end{array}$ \\
\hline Rear Spacer & R-09 & $\begin{array}{c}\text { Machining } \\
\text { Grinding }\end{array}$ & $\begin{array}{l}\text { Attached to Axle } \\
\text { Floating }\end{array}$ \\
\hline $\begin{array}{c}\text { Rear Axial } \\
\text { Bearing Mount }\end{array}$ & $\mathrm{R}-10$ & $\begin{array}{l}\text { Machining } \\
\text { Grinding }\end{array}$ & $\begin{array}{l}\text { Attached to axle with } \\
\text { vacuum braze } \\
\text { Floating without } \\
\text { attachment }\end{array}$ \\
\hline
\end{tabular}


Table 5. Component Fabrication and Joining Options (2)

\begin{tabular}{|c|c|c|c|}
\hline Part & $\begin{array}{c}\text { Module } \\
\text { Designation }\end{array}$ & Fabrication Methods & Joining Options \\
\hline Rear Rotor-Can & $\mathrm{R}-11$ & $\begin{array}{l}\text { Sheet rolled (hydroform) } \\
\text { Welding }\end{array}$ & $\begin{array}{l}\text { Joined to axle with circular weld (or } \\
\text { vacuum braze gold/nickel) } \\
\text { Joined to rear rotor-can with circular } \\
\text { weld and grind }\end{array}$ \\
\hline Stator-Can & S-01 & $\begin{array}{l}\text { Sheet rolled (hydroform) } \\
\text { Welding }\end{array}$ & $\begin{array}{l}\text { Hydrostatically formed into Stator } \\
\text { assembly to fit and attach to Stator, } \\
\text { or } \\
\text { Chill and fit at back of Rotor (interface } \\
\text { with End Cap), using load bolt } \\
\text { fasteners to attach to coupler. }\end{array}$ \\
\hline $\begin{array}{l}\text { Rear Touchdown } \\
\text { Bearing }\end{array}$ & S-02 & $\begin{array}{c}\text { Cast } \\
\text { Intended to float, slot or } \\
\text { groove in Stator-Can to } \\
\text { facilitate base that slides into } \\
\text { Stator-Can and protrudes out } \\
\text { providing Rotor gap. }\end{array}$ & Floating \\
\hline $\begin{array}{l}\text { Rear Bearing } \\
\text { Mount }\end{array}$ & S-03 & $\begin{array}{l}\text { Sheet rolled (hydroform) } \\
\text { Welding }\end{array}$ & $\begin{array}{c}\text { Bolted fasteners to End Cap and Motor } \\
\text { Mount }\end{array}$ \\
\hline $\begin{array}{l}\text { Rear (radial) } \\
\text { Bearing } \\
\text { (windings) }\end{array}$ & S-04 & Standard lamination practices & Standard laminations practices \\
\hline Motor Mount & S-05 & $\begin{array}{l}\text { Sheet rolled (hydroform) } \\
\text { Welded }\end{array}$ & $\begin{array}{c}\text { Bolted fasteners to End Cap and Motor } \\
\text { Mount }\end{array}$ \\
\hline Stator Windings & S-06 & Standard lamination practices & Standard lamination practices \\
\hline $\begin{array}{c}\text { Front Bearing } \\
\text { Mount }\end{array}$ & S-07 & $\begin{array}{l}\text { Sheet rolled (hydroform) } \\
\text { Welding }\end{array}$ & $\begin{array}{c}\text { Bolted fasteners to End Cap and Motor } \\
\text { Mount }\end{array}$ \\
\hline Coupler & C-01 & $\begin{array}{l}\text { Sheet rolled (hydroform) } \\
\text { Welding } \\
\text { Two flat plates welded to tube } \\
\text { centered and machined } \\
\text { ground true. }\end{array}$ & Bolted to Pump case and Impeller case \\
\hline $\begin{array}{l}\text { Front Axial } \\
\text { Bearings }\end{array}$ & C-02 & $\begin{array}{l}\text { Inlay split ring shape of } \\
\text { insulating layer, bearing and } \\
\text { windings into Coupler }\end{array}$ & $\begin{array}{l}\text { Tight fit cold and loose fit hot with } \\
\text { backing plate. Attached with fasteners } \\
\text { into Coupler }\end{array}$ \\
\hline
\end{tabular}


Table 6. Component Fabrication and Joining Options (3)

\begin{tabular}{|c|c|c|c|}
\hline Part & Module Designation & Fabrication Methods & Joining Options \\
\hline $\begin{array}{c}\text { Front Touchdown } \\
\text { Bearing }\end{array}$ & C-03 & $\begin{array}{c}\text { Cast } \\
\text { Intended to float, slot or } \\
\text { groove in Stator-Can to } \\
\text { facilitate base that slides into } \\
\text { Stator-Can and protrudes out } \\
\text { providing Rotor gap. }\end{array}$ & Floating \\
\hline End Cap & E-01 & $\begin{array}{c}\text { Sheet rolled (hydroform) } \\
\text { Welding }\end{array}$ & $\begin{array}{c}\text { Bolted fasteners to Rear } \\
\text { Bearing Mount }\end{array}$ \\
\hline Rear Axial Bearings & E-02 & $\begin{array}{c}\text { Inlay split ring shape of } \\
\text { insulating layer, bearing and } \\
\text { windings into End Cap }\end{array}$ & $\begin{array}{c}\text { Tight fit cold and loose } \\
\text { fit hot with backing plate. } \\
\text { Attached with fasteners } \\
\text { into End Cap }\end{array}$ \\
\hline
\end{tabular}

Table 7. Identified Component Issues - Design, Materials, Fabrication, or Joining (1)

\begin{tabular}{|c|c|c|}
\hline Part & Module Designation & Design and Fabrication Issues \\
\hline Axle & R-01 & $\begin{array}{c}\text { Material Availability } \\
\text { Assembly Sequence and Distortion }\end{array}$ \\
\hline Impeller & R-02 & $\begin{array}{c}\text { Material Availability } \\
\text { Ability to remove after operation for maintenance } \\
\text { Match in materials with Case }\end{array}$ \\
\hline Front Rotor-Can & Resign must provide proper fit at working temperature \\
\hline $\begin{array}{c}\text { Front Axial Bearing } \\
\text { Mount }\end{array}$ & R-04 & $\begin{array}{c}\text { Material Availability } \\
\text { Assembly and Order }\end{array}$ \\
\hline Front Spacer & CTE must avoid Rotor penetrating can
\end{tabular}


Table 8. Identified Component Issues - Design, Materials, Fabrication, or Joining (2)

\begin{tabular}{|c|c|c|}
\hline Part & $\begin{array}{c}\text { Module } \\
\text { Designation }\end{array}$ & Fabrication Methods \\
\hline Stator-Can & S-01 & $\begin{array}{l}\text { Weld bead on outside to avoid seam affecting inside. } \\
\text { How is back of rotor secured or located? } \\
\text { Brazed drain plug on back end to enable draining. }\end{array}$ \\
\hline $\begin{array}{l}\text { Rear Touchdown } \\
\text { Bearing }\end{array}$ & S-02 & $\begin{array}{l}\text { Matched set required to obtain proper clearance. } \\
\text { May need multiple sets of different dimensions to provide an adjustment. }\end{array}$ \\
\hline $\begin{array}{c}\text { Rear Bearing } \\
\text { Mount }\end{array}$ & S-03 & r \\
\hline $\begin{array}{c}\text { Rear (radial) } \\
\text { Bearing (windings) }\end{array}$ & S-04 & $\begin{array}{l}\text { Estimate number of turns, electrical current etc. } \\
\text { This will determine wire gauge and space requirements. }\end{array}$ \\
\hline Motor Mount & S-05 & None \\
\hline Stator Windings & S-06 & $\begin{array}{l}\text { Estimate number of turns, electrical current etc. } \\
\text { This will determine wire gauge and space requirements. }\end{array}$ \\
\hline $\begin{array}{l}\text { Front Bearing } \\
\text { Mount }\end{array}$ & S-07 & None \\
\hline Coupler & C-01 & $\begin{array}{l}\text { Requires heating to avoid salt solidification. } \\
\text { Requires spring-loaded Nickel gaskets. }\end{array}$ \\
\hline $\begin{array}{l}\text { Front Axial } \\
\text { Bearings }\end{array}$ & $\mathrm{C}-02$ & $\begin{array}{c}\text { Bearing/windings must be integral to Coupler } \\
\text { Windings must avoid Coupler/salt temperature } \\
\text { Geometry limits choice for bearing/ windings shape } \\
\text { CTE limits attachment options }\end{array}$ \\
\hline $\begin{array}{l}\text { Front Touchdown } \\
\text { Bearing }\end{array}$ & C-03 & $\begin{array}{l}\text { Matched set required to obtain proper clearance. } \\
\text { May need multiple sets of different dimensions to provide an adjustment. }\end{array}$ \\
\hline End Cap & E-01 & Requires heating to avoid salt solidification on Stator-Can \\
\hline $\begin{array}{l}\text { Rear Axial } \\
\text { Bearings }\end{array}$ & E-02 & $\begin{array}{c}\text { Bearing/windings must be integral to Coupler } \\
\text { Windings must avoid End Cap/salt temperature } \\
\text { Geometry limits choice for bearing/ windings shape } \\
\text { CTE limits attachment options }\end{array}$ \\
\hline
\end{tabular}

\subsubsection{Fabrication Methods}

Many of the components of the canned rotor pump share common fabrication methods. Such components include the axle (R-01), the impeller (R-02), the front and rear axial bearing mounts (R03 and R-10), the front, rear, middle front, and middle rear spacers (R-05, R-09, and R-07). For these components, machining and grinding are suggested. Machining typically consists of cutting a raw work-piece of material into the desired shape and form by material removal processes. These processes can include drilling, turning, and grinding. Grinding is a traditional process in which a grinding wheel is used to cut the material. It is considered an abrasive machining process.

Non-traditional machining processes considered for the axle's spline include electrical discharge machining (EDM), and water-jet cutting. The EDM process consists of cutting or molding a material to a desired shape by using controlled electrical discharges. Material is shaped by electrically charged electrodes, and the removed material is washed away using a dielectric fluid. The waterjet cutter process uses ultra-high pressurized water to cut the material, or a mix of water and an abrasive substance for cutting harder materials.

Components such as the front and rear rotor-cans (R-03 and R-11), stator-can (S-01), rear and front bearing mounts (S-03, S-07), motor mount (S-05), coupler (C-01), and end cap (E-01) share the fabrication methods of sheet rolling, hydroform, and welding. The rolling process consists of shaping 
a material sheet by passing it through a series of paired rollers. The rolling process may be accomplished as hot or cold, depending on the temperature of the material. The differentiation between hot and cold is whether the material is above or below its recrystallization temperature. Cold rolling of steel, for example, increases the strength via strain hardening up to 20 percent. In hot rolling, scale is often produced. The finished tolerances on hot rolled steels are looser than that of cold rolled. Hydroforming is a process that shapes ductile materials into stiff pieces. This shaping occurs by placing the sheet of material over a mold and applying a high-pressure hydraulic liquid to press the material into conformance, giving it the specific desired shape. Hydroforming allows complex shapes to be formed that would be difficult or impossible with solid die stamping. Welding consists of joining two work pieces into a single piece by melting them and adding a filler material that strengthens the joint after cooling. Pressure may be used with heat if it is necessary for the weld. Many welding methods are possible; each welding method offers particular benefits. Methods include electric arc, resistance (e.g., spot and seam), energy beam (e.g., laser and electron beam), ultrasonic, and friction welding.

Standard lamination processes are suggested for the bearing rotor (R-06), rotor laminations (R-08), rear (radial) bearing (windings) (S-04), and the stator windings (S-06). Lamination consists of manufacturing a material in multiple layers. These are assembled together using different methods. Although lamination is often used to fabricate composites of high strength, the primary reason for laminating the magnetic materials is to inhibit the flow of eddy currents induced by an external magnetic field by forcing them along a high resistance path through the laminations. The laminations are arranged to be parallel with the lines of magnetic flux.

Casting is suggested for components such as the rear and front touchdown bearings (S-02, C-03). The casting method consists of pouring a liquid material (in this case ceramic) into a mold with the desired shape, which then solidifies.

The front and rear axial bearings (C-02, E-02) suggest a split ring inlay of insulated layer with the bearings and the windings.

The stator windings for magnetic drive and bearings are fabricated by winding high temperature glass insulated copper wire on a ceramic solenoid bobbin. The challenge in fabricating the wire coil assemblies is removing the moisture (and other contaminants) that would degrade the windings in operation at temperature. The solenoid wire is coated with a multi-component oxide and wound to the correct number of turns. Several parallel wires are wound concurrently to form a Litz-type highfrequency conductor. Alternatively, the wire may be purchased as a Litz-style conductor from the manufacturer. Connection leads are brought out for termination and connection to lower temperature wires that, in turn, connect to the drive electronics. The wound bobbin is potted and vacuum cured at elevated temperature to remove moisture. The leading candidate potting material for the glass-coated wires is Ceramacast 584 from Aremco Products. Alternatively, the coils may be purchased as an assembled component.

\subsubsection{Joining and Attachment Options}

The joining option of internal threading is suggested for the end of the impeller (R-02) to be attached to the axle. Threading consists of cutting a screw thread by grinding. Another option is to join impeller to axle by spline fit by use of a fastening nut.

The front and rear rotor-cans (R-03, R-11), and front and rear axial bearing mounts (R-04, R-10) are joined by vacuum braze. This joining option is accomplished by heating a filler metal (such as nickel or gold) above its melting point and distributing it between two base metals. The filler metal is then 
cooled joining the pieces together. The process is carried out in a vacuum furnace. In addition to this method, the front and rear rotor-cans (R-03, R-11) are suggested to be attached with a circular weld and grind. The front and rear axial bearing mounts may be floating without any attachment.

The stator-can has the option of being hydrostatically formed into the stator or chilled and fixed at the back of the rotor using load bolt fasteners to attach to the coupler. Bolted fasteners can be used to attach the rear and front bearing mounts (S-03, S-07), the coupler (C-01) and the end cap (E-01) to their respective mating components: the end cap and motor mount (for the rear and front bearing mounts), to the pump case and the impeller case (for the coupler) and to the rear bearing mount (for the end cap). Standard lamination processes are suggested for the attachment of the rear (radial) bearing (windings) and the stator windings. The front and rear axial bearings are suggested to be joined by tight fit cold and loose fit hot with a backing plate, and attached into coupler and end cap (for the rear axial bearings) using fasteners.

Several components have no joining options since they are floating in the design concept of the pump. These components are the front, rear, middle front and middle rear spacers (R-05, R-09, and R-07), the rotor laminations (R-08), and the rear and front touchdown bearings (S-02, C-03).

\subsubsection{Fabrication Issues}

Fabrication issues are discussed below by component.

\section{Axle}

The axle transmits torque from the switch reluctance motor to all components in the rotor assembly; hence, its balance is critical for precise rotation and position. For this reason, manufacturing methods used to fabricate it must be able to achieve the specified tolerances. As it will be exposed to salt, a corrosion resistant material must be used and the chosen manufacturing processes must be able to work the specified material.

The axle will also support axial and radial bearing laminations, as well as rotor laminations, spacers and the impeller. As the components will be exposed to high temperatures $\left(650{ }^{\circ} \mathrm{C}-700{ }^{\circ} \mathrm{C}\right)$, they will undergo thermal expansion, and the axle design must dimensionally accommodate for expansion. Additionally, mismatch between coefficients of thermal expansion may result in faulty attachments between components when high temperatures are reached, hence assembly methods must be chosen accordingly.

\section{Rotor-can}

The rotor-can protects the motor components from contact with the fluid. To prevent motor-stator rubbing, and to assure magnetic field penetration, it is necessary to maintain the fluid gap within the specified dimension. The fluid gap is between the rotor and stator-cans; hence, it is crucial that the rotor-can is machined to the specified tolerances and that the rotor-can dimensions account for thermal expansion. To ensure magnetic field penetration, the can must be very thin (of the order of a millimeter). Manufacturing of such a thin cylinder may present complexities. Additionally, the manufacturing process must be compatible with the chosen non-corrosive material.

The rotor-can will be attached to the outer surface of the components of the rotor assembly. As the can will be attached to several components, mismatch between coefficients of thermal expansion 
must be accounted for in order to prevent detachment. As parts of the can will be welded together, the thermal effects of welded joints must be evaluated.

\section{Axial Bearing Mounts}

The inner axial bearing 'axial bearing mount' will contain the magnetic material of the axial bearing. A tapered magnetic ring would be beneficial for load support, but it will introduce manufacturing and assembly issues with a tapered axial bearing mount, as it will require additional parts and assembly points.

The assembly method of the magnetic material could be welding or threading. Thermal effects of each of those must be assessed as high temperatures will degrade magnetic properties.

\section{Inner Bearing Laminations}

The bearing inner laminations are rotational components that will be critical to motor positioning, so machining errors must be minimized, and specified tolerances must be achieved. Internal stresses produced by manufacturing processes may result in poor performance; hence, they should be relieved by annealing. Bearing laminations will be welded together so thermal effects on welds must be taken into account.

The laminations will also be attached to the axle, so thermal effects on that particular attachment must be evaluated.

\section{Rotor Laminations}

Non-magnetic, high electrical resistance material between the rotor laminations could be beneficial to provide support and aid in balance. Rotor spacers could be re-designed and utilized for this purpose. Like bearing laminations, rotor laminations will be welded together and attached to the axle. Thermal effects on the attachments must be taken into account.

Tolerances of 25.4 micrometers ( 0.001 inches) must be achieved in order to prevent excessive deflections and maintain the desired fluid gap. Manufacturing processes must be chosen accordingly. In addition, internal stresses produced by manufacturing processes may result in poor performance; hence, they should be relieved by annealing.

Welding and press fits are options for assembly with axle and rotor-can, as well as lamination attachments, hence, thermal effects of welded joints and interference fits must be considered.

\section{Stator-Can}

The stator-can protects stator components from contact with the fluid. Because it will be exposed to the fluid, a non-corrosive material must be used for the stator-can, so compatibility of this material with the manufacturing processes must be evaluated. As with the rotor-can, tolerances of 25.4 micrometers ( 0.001 inches) will be needed to guarantee the required fluid gap. The stator-can must be thin in order to allow penetration of magnetic field (order of a millimeter) and manufacturing such thin metal with high tolerances may present difficulties. In addition, the stator-can will be welded together, and welding seams may affect inner components; hence, they should be welded outside. Further, to enable draining of fluids, a drain plug may be included in the design. 
The stator-can will be attached to the stator components, so thermal effects must be considered for attachment options (welded joints or interference fits). Effects of mismatch of coefficient of thermal expansion (CTE) between components of stator assembly should also be taken into account when setting dimensions and choosing assembly methods.

\section{Catcher Bearings}

Catcher bearings must provide protection to the motor in case of impact due to either radial or axial bearing failure. For this reason, an L-shaped or a tapered bearing may be used. To avoid machining thin sections of the bearing in the gap between axial bearings, the front and end of the axle must be designed with a matching shape. This design may introduce complications in the axle manufacturing. As catcher bearings will be in the fluid gap, manufacturing method must ensure that tolerances are achievable, in order to allow proper fluid flow.

\section{Motor Mount}

The stator mount encloses all motor components. It will be attached to the molten salt loop. Manufacturing and assembly must prevent any accidental leakage to the environment. Flexitallic gaskets will be used between the sections of the motor for this purpose. Additionally, spaces for the stator windings must be included. If fasteners are used for connecting the sections of the mount, thermal effects on fasteners must be evaluated.

\section{Stator Laminations/ Stator Windings}

The stator laminations, along with the rotor laminations, will control the Switch Reluctance Motor torque production. Tolerances of 25.4 micrometers ( 0.001 inches) must be achieved in order to prevent excessive deflections and maintain the desired fluid gap. Laminations will be welded together

and attached to the axle, so thermal effects on the attachments must be taken into account. In addition, internal stresses produced by manufacturing processes may result in poor performance; hence, they should be relieved by annealing.

The stator-can is attached to these laminations. This attachment must not negatively affect the laminations structurally or magnetically. Insulation between the windings must be used for temperature protection, hence assembly of insulation material must be considered.

\section{Coupler / End Cap}

To avoid molten salt solidification, high temperatures at mount must be maintained. Flexitallic gaskets will also be necessary to avoid leakage and fasteners will be used to join with other components so thermal effects must be studied accordingly. Outer axial bearings will be contained in the coupler and end cap; hence, leakage to these components must be prevented. An Alloy $\mathrm{N}$ thin plate can be attached (welded or fastened) to the axial bearing in order to prevent leakage, so thermal effects on those assembly methods must be taken into account as well.

\subsection{ASSEMBLY SEQUENCE}

The section describes the overall pump assembly on a modular basis. The parts are assembled together into modules; the modules are assembled to complete the pump. 


\section{Rotor Assembly}

Most components in the rotor assembly (axial bearings, radial bearings, rotor laminations, spacers and impeller) will be mounted on the axle and torque will be transmitted via its spline feature (see Figure 10). A step on the axle will separate the designated location for the front axial bearing and the rest of the components. For this reason, the front spacers, front radial bearings, rotor laminations, rear spacers and rear bearings will be slid over the spline feature in that order from rear to front. The rear axial bearing will be slid on its designated position afterwards. The front axial bearing can be slid into position from rear to back and then rotor-can assembly may proceed. The rotor-can will be divided into separate pieces for assembly purposes. The front of the rotor-can will be slid into the rotor assembly and then the rear rotor-can will be assembled from the opposite end. A circular weld will be used for joining both pieces. Note that once the rotor-can is assembled, it should not be disassembled as the welded joints are meant to be permanent attachments. The impeller will not be assembled in the axle until other components of the stator assembly are in place.

Alternative designs that have been considered for some components, such as incorporating both axial bearings in the front of the axle, and tapered axial bearings, may present assembly issues and over constraints regarding the assembly sequence.

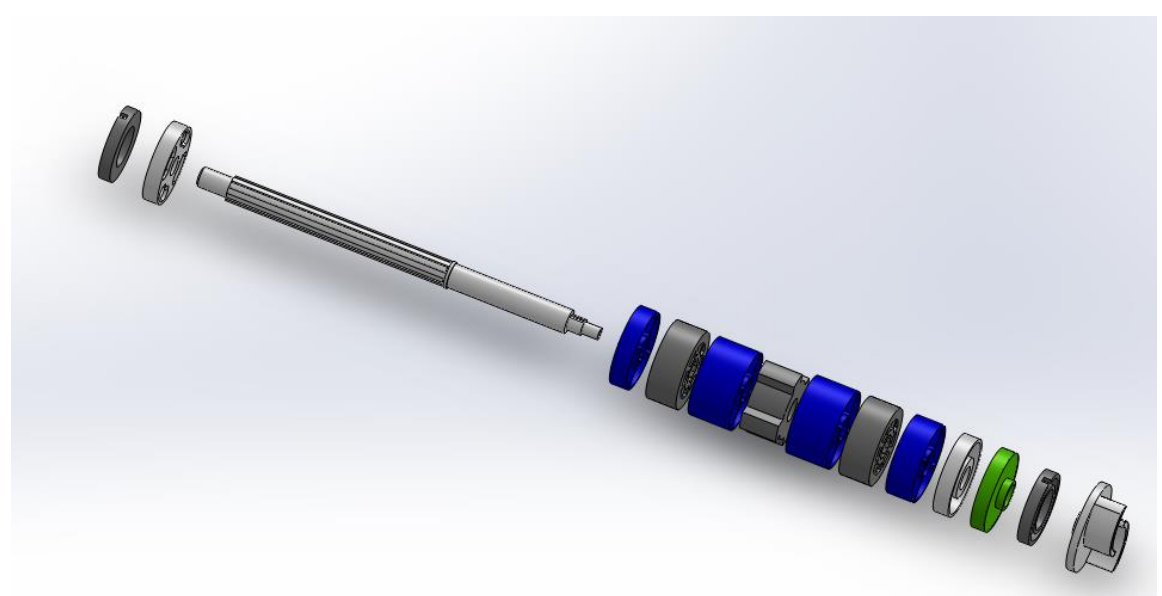

Figure 10. Exploded view of rotor components.

\section{Stator Assembly}

The motor mount will support the stator assembly components: radial bearing laminations, spacers, stator laminations windings and the stator-can (see Figure 11). The motor mount will be divided into different sections: the front stator will contain the front outer radial bearing laminations and windings, the middle section will contain the stator laminations and windings, and the rear section will contain the rear outer radial bearing laminations and windings. Sections will be joined by fasteners and spacers will be placed between them. The stator-can will be separated into two parts the front statorcan will be slid to the complete assembly and welded to the stator components. The stator-can cannot be closed until the stator assembly is joined to the rotor assembly. 


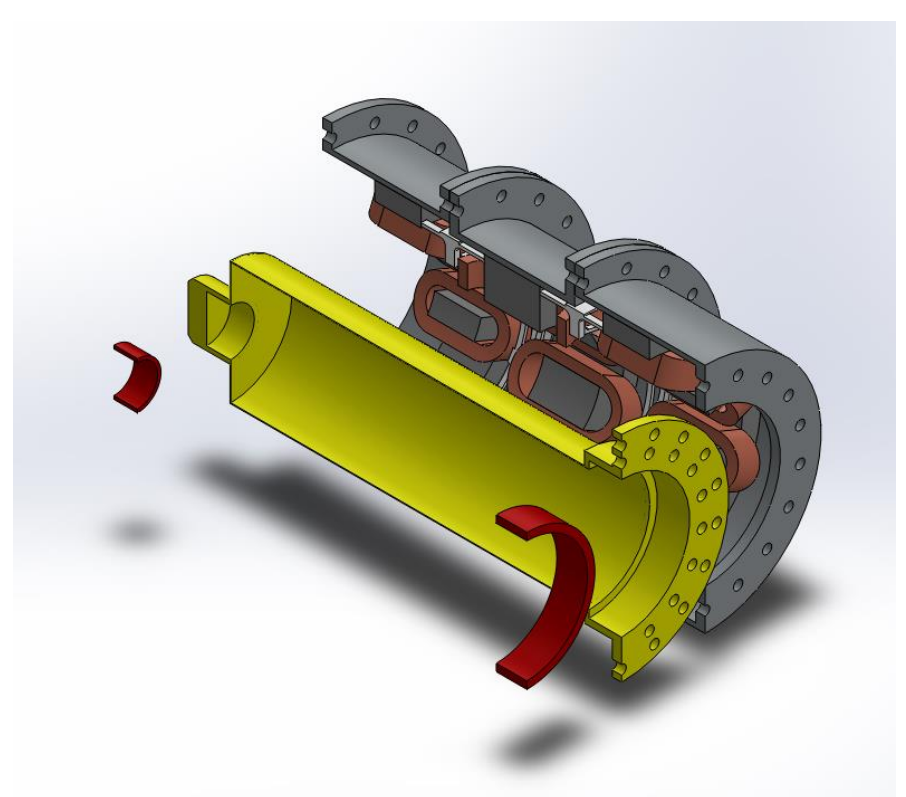

Figure 11. Exploded cross-section of stator assembly.

\section{Stator-Rotor Assembly}

The rotor assembly will be slid into the stator assembly and catcher bearings will be slid between the two cans (rear and front). At this point, the stator-can may be closed and the rear rotor-can will be welded to the front stator-can. The stator-can may not be disassembled beyond this point. Note that catcher bearings will be floating; hence, their position must be secured during the assembly process.

\section{Coupler Assembly}

The coupler will support the outer front axial bearing, which will be slid into a corresponding sleeve incorporated into the coupler. The axial bearing must have a sealing mechanism, like an Alloy $\mathrm{N}$ plate, because this portion of the motor will be exposed to the fluid. Other designs, such as a sleeve opened at the opposite side of the coupler, would aid assembly and reduce the number of parts, but it would introduce manufacturing challenges - as a thin section of the coupler would be difficult to fabricate.

\section{End Cap Assembly}

The End Cap of the motor will support the rear axial bearing, which will be slid into a corresponding sleeve incorporated into the end cap. The axial bearing must have a sealing mechanism, like an Alloy $\mathrm{N}$ plate, since this portion of the motor will be exposed to the fluid. Other designs, such as a sleeve open at the opposite side of the End Cap would aid assembly and reduce the number of parts, but it would introduce manufacturing challenges - as a thin section of the End Cap would be difficult to fabricate.

\section{Coupler/End Cap- Motor Mount Assembly}

Both the coupler and the End Cap will be joined to the motor mount with fasteners by the front and rear of the motor respectively. 


\section{Impeller/Impeller Mount Assembly}

The pump impeller is connected to the axle, followed by the impeller mount, which will be joined to the coupler through fasteners (see Figure 12). Note that the impeller and mount must be the last components to be included in the assembly. This sequence allows other components (axial bearings and coupler) to be assembled correctly. For future impeller maintenance, the impeller attachment must be reversible.

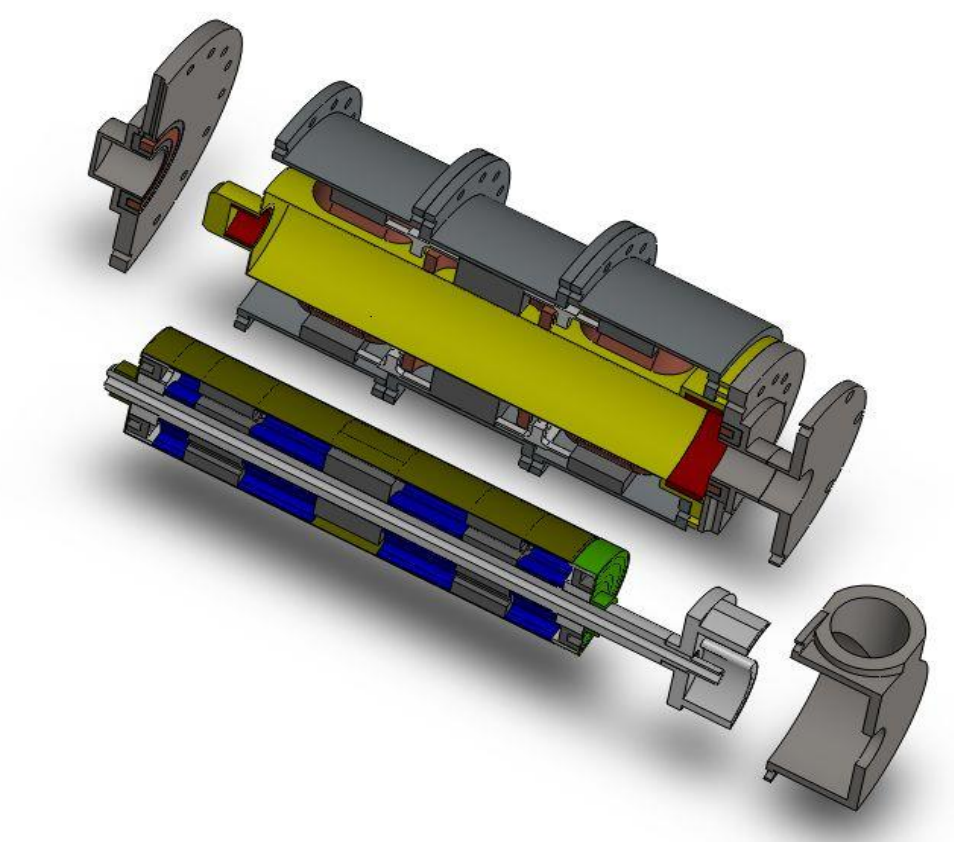

Figure 12. Exploded cross-section view of pump module integration. 


\section{DRIVE ELECTRONICS}

\subsection{BACKGROUND}

The switched reluctance motor is a machine that has a simple yet robust construction, but with the disadvantage of control complexity. The control of a switched reluctance motor requires high fidelity feedback measurements, a control method that is based on the motor behavior, and the appropriate drive electronics. The switched reluctance motor (SRM) drive system consists of the motor, a power converter, a digital controller, and the rotor position sensors. ${ }^{1,5}$ A general block diagram of the complete drive system is shown in

Figure 13.

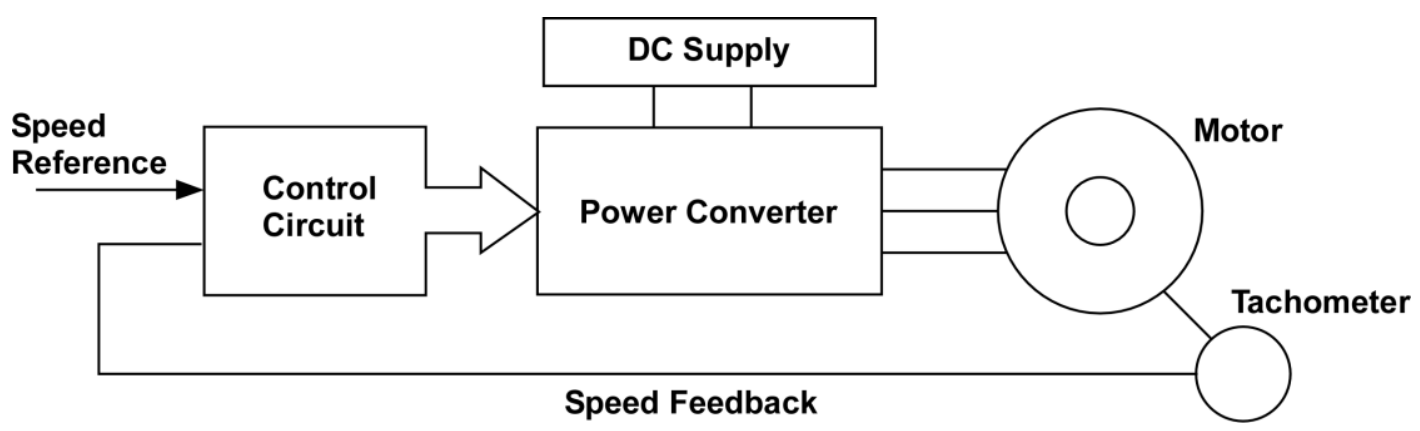

Figure 13. Block diagram of drive system.

The power converter itself consists of the main power stage, where the energy drawn from the source flows to the motor and the control section, which regulates power flow. ${ }^{6}$ Although a number of conventional converters for switched reluctance motors are available, different topologies for converter power stages have been researched and developed over the years. ${ }^{5}$ A classification and analysis of the SR converters was conducted by Ahn, Liang and Lee in reference five. ${ }^{5}$ The most typical converter topology for switched reluctance motors is the Asymmetrical Bridge, shown in Figure 14.

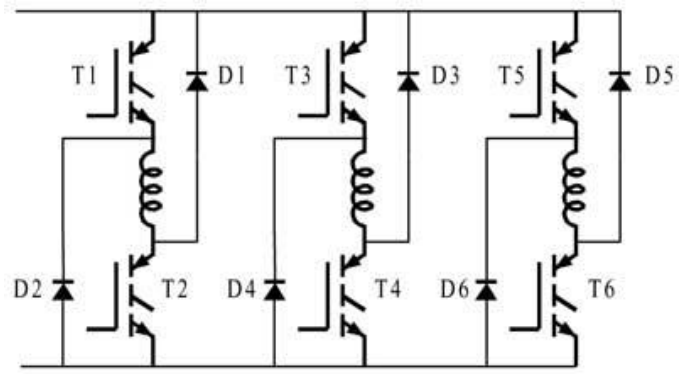

Figure 14. Asymmetric Bridge Converter. (The coils shown are the motor windings.)

When the upper and lower electronic switches of a phase of this converter (say $\mathrm{T}_{1}$ and $\mathrm{T}_{2}$ ), are turned on, a current will start circulating through that specific phase, actuating it. When the circulating 
current exceeds the set current value, the switches are turned off. The energy stored in the motor's windings will keep the current in the same direction until the energy decays. The diodes on that phase become forward biased and the source is recharged, lowering the current below the set value. However, the frequent turn-on and turn-off of the switches on a phase for energy exchange causes an increase in the switching losses of the switches. These switching losses can be minimized with snubbers. Nevertheless, this converter is considered ideal for high-power applications. ${ }^{7}$ The control section of the converter employs a closed-loop feedback system for winding current control.

\subsection{GROUP DESIGN PROPOSITION}

As part of the design of the switched reluctance motor for the canned rotor pump, a drive electronics system was proposed based on the motor's corresponding voltage, current, power rates, as well as, the nominal switching frequency.

A block diagram of the switched reluctance motor speed control is shown in Figure 15 with a focus on the drive electronics on the upper right. The converter shown in the figure is a three-phase converter with a half bridge topology, consisting of two insulated-gate bipolar transistors (IGBT) and two diodes per phase. A full H-bridge topology is shown in Figure 16.

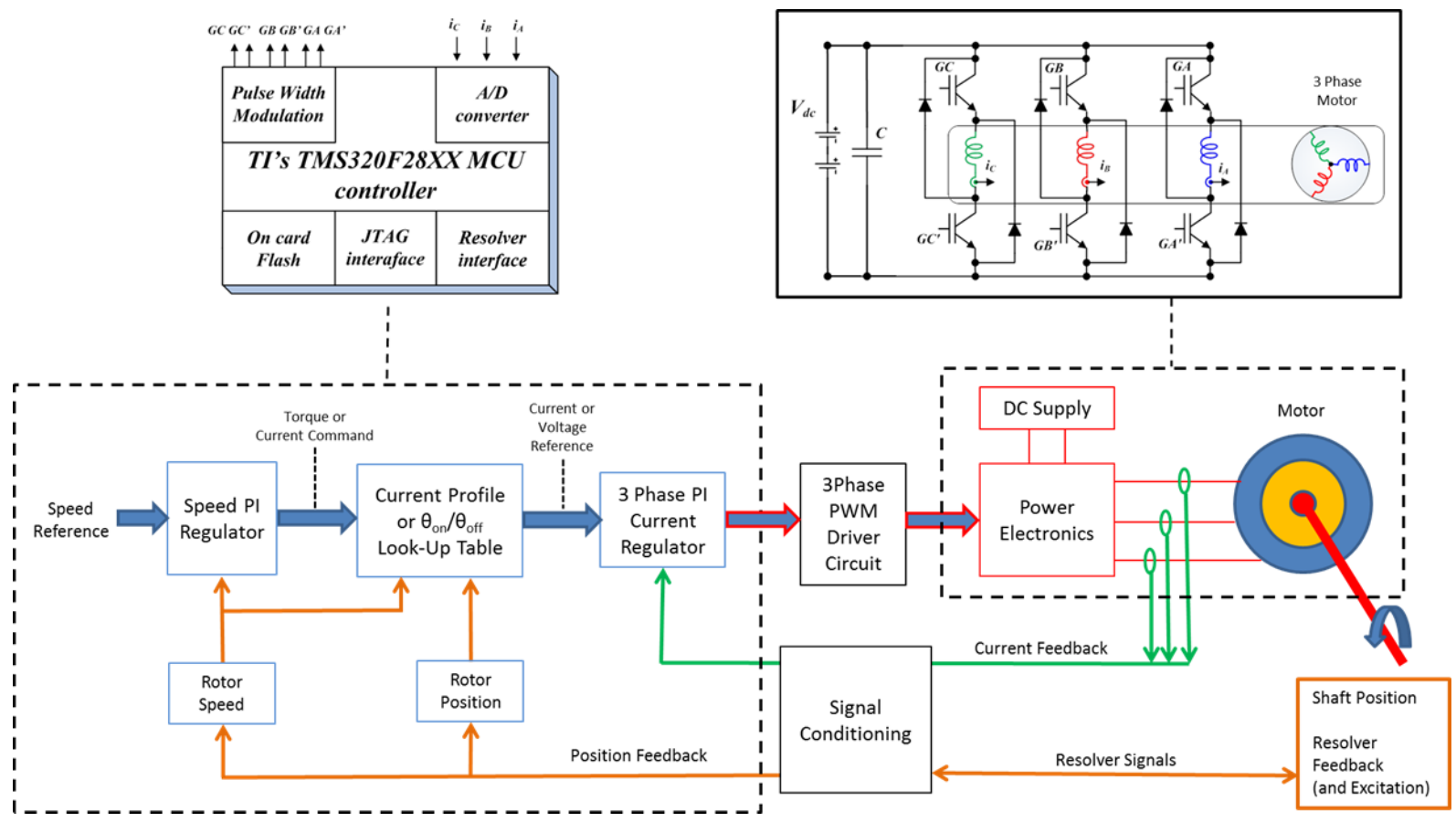

Figure 15. SRM speed control block diagram. 


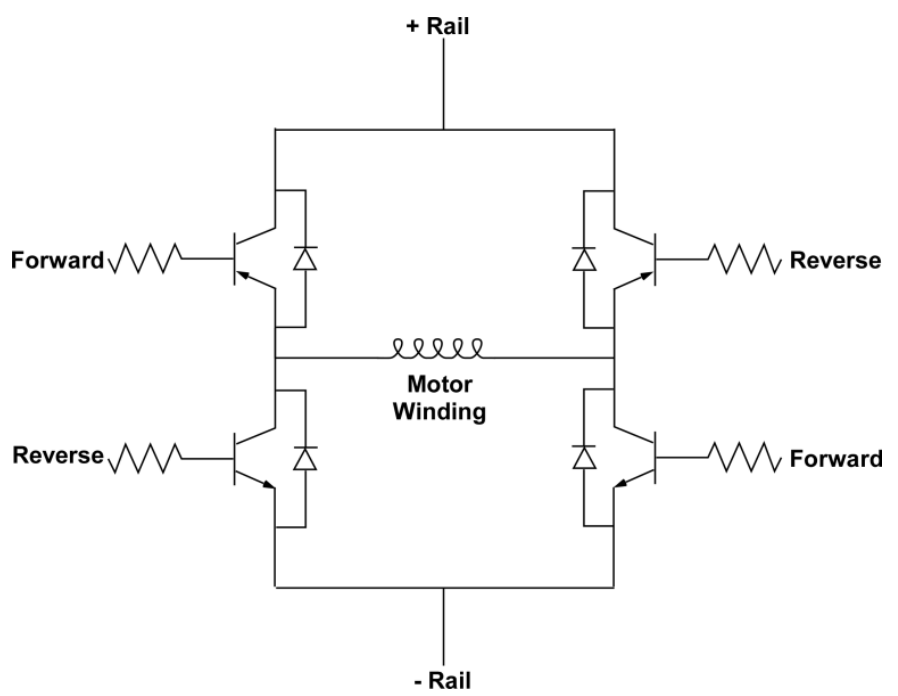

Figure 16. Full H-Bridge driver topology.

Control of the switched reluctance motor entails sending phase steering signals to the upper IGBTs, which are connected to the positive DC link, and phase current modulation signals to the lower IGBTs, which are connected to the phase windings finish. Phase steering signals sequence the stator windings current in relation to the rotor position sensor signal so current builds up in the phase coils during an interval when a rotor pole pair are unaligned to the phase. Three switching states are considered for current regulation: (1) hard chopping, (2) soft chopping, and (3) pulse width modulation (PWM).

As part of the manufacturability assessment, a survey of potential SRM drive electronics offerings was undertaken. This survey was targeted to evaluate whether there are commercial modules that meet the electrical conditions of this design.

The conceptual design of the SRM motor was used to estimate characteristics for the magnetic, electrical, and mechanical requirements. The estimates are as follows:

- Voltage: $325 \mathrm{~V}$ DC

- Current: $~ 84 \mathrm{~A}$

- Continuous Power Rating: $10 \mathrm{~kW}$

- Switching Frequency: $f_{s}=10 \mathrm{kHz}$

The survey of commercially available hardware led to several findings about the current industrial offerings. A variety of commercially available converters for switched reluctance drives is available. A search for IGBT converter modules with the half or full H-Bridge topology resulted in finding the following modules.

1. The Powerex POW-R-PAK ${ }^{\mathrm{TM}}$ : a configurable IGBT assembly that can be used as a converter, chopper, half or full bridge or three-phase inverter for motor control, and other power conversion applications. This assembly features IGBTs with low switching losses, an integrated gate drive, output current measurement and feedback, and shoot through detection, among other features. It is suitable for operation with DC link voltages up to $400 \mathrm{~V}$ and switching frequencies over $20 \mathrm{kHz}$.

2. Powerex Four IGBTMOD ${ }^{\mathrm{TM}} \mathrm{U}_{\text {-Series Module: }}$ it consists in four IGBTs configured in an HBridge, designed for switching applications in motor control. It is suitable for operations up to $600 \mathrm{~V}$ and $100 \mathrm{~A}$. A compatible gate driver for this module is the Powerex VLA504-01. 
3. IXYS SOT-227B Power GenX3 ${ }^{\mathrm{TM}}$ B3 IGBT: Used for power inverter application and motor drives, this IGBT is suitable for operation with voltages up to $600 \mathrm{~V}$ and switching frequencies up to $40 \mathrm{kHz}$. A compatible gate driver for this IGBT is the IXYS IX2127 HighVoltage IGBT Driver.

The challenge of finding suitable commercially available modules lies in the electrical specifications of the motor. Both high voltage and current may limit the acceptable commercially available products leaving only a small number of modules that could be used in this design.

\section{CONCLUSIONS AND NEXT STEPS}

This report documents and summarizes an assessment of the manufacturability of the highly instrumented canned rotor, magnetic bearing pump conceptual design. The design of this pump combines materials, electronics, thermal management, mechanics, hydraulics, sensors, and controls. Integrating the instrumentation and control deeply into the pump design is necessary for its functioning.

The report includes an outline of the underlying pump function, listing of pump component materials and fabrication processes. The report also documents engineering drawings of first generation prototype components. No fundamental barriers to constructing the pump have been identified. Candidate materials and suppliers to meet each design requirement are commercially available. However, only a high-level evaluation of manufacturing issues has yet been performed. As the pump design progresses, a more detailed and complete fabrication plan will need to be created.

The next step in the overall construction and demonstration of the embedded I\&C pump is to complete the integrated modeling and simulation followed by constructing an initial low-temperature physical prototype. Operation of the prototype will permit refinement of the models, which leads to construction and operation of a high-temperature prototype pump. 


\section{REFERENCES}

1. Kisner, R., et al., Embedded Sensors and Controls to Improve Component Performance and Reliability Conceptual Design Report, ORNL/TM-2012/433, September 2012, http://info.ornl.gov/sites/publications/files/Pub39248.pdf

2. Kurt A. Polzin, "Liquid Metal Pump Technologies for Nuclear Surface Power," Proceedings of Space Nuclear Conference 2007, Boston, Massachusetts, June 24-28 2007, Paper 2002.

3. A. Chiba, T. Fukao, O. Ichikawa, M. Oshima, M. Takemoto, and D. G. Dorrell, Magnetic Bearings and Bearingless Drives, Elsevier, 2005.

4. Praveen Vijayraghavan, Design of Switched Reluctance Motors and Development of a Universal Controller for Switched Reluctance and Permanent Magnet Brushless DC Motor Drives, PhD Dissertation, Virginia Polytechnic Institute and State University, November 2001.

5. Ahn, J.W., Liang J., and Lee D.H., "Classification and Analysis of Switched Reluctance Converters", Journal of Electrical Engineering \& Technology 5 (2010).

6. Hughes, A., Electric Motors and Drives, Elsevier Newnes, 2006, pp. 45-46.

7. Krishnan, R., Switched Reluctance Motor Drives, CRC Press, 2001, pp.173-174,177. 
APPENDIX A 


\section{A.1 COMPONENT ENGINEERING DRAWINGS}

\section{A.1.1 - Component Axle, R-01}

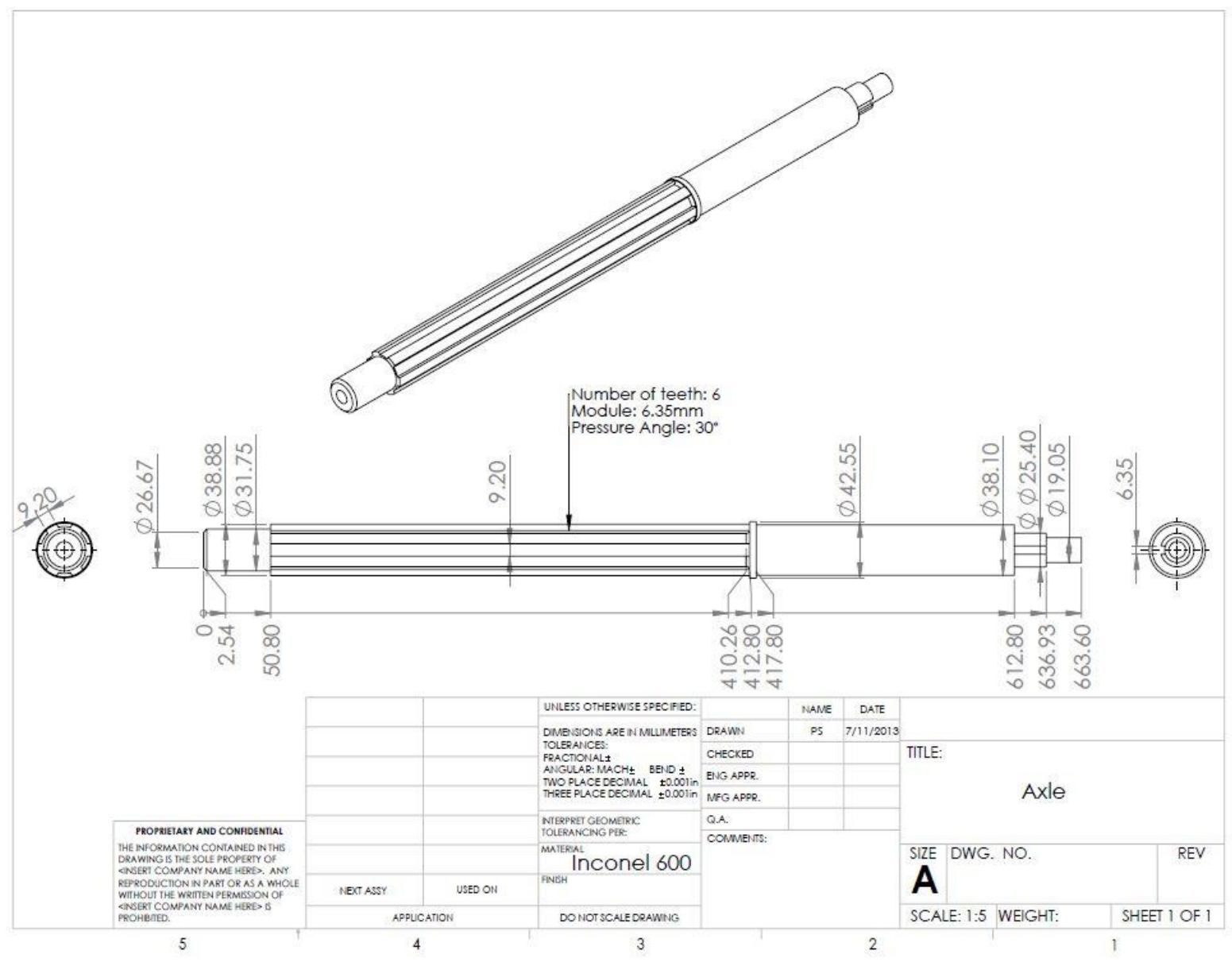




\section{A.1.2 - Component Impeller, R-02}

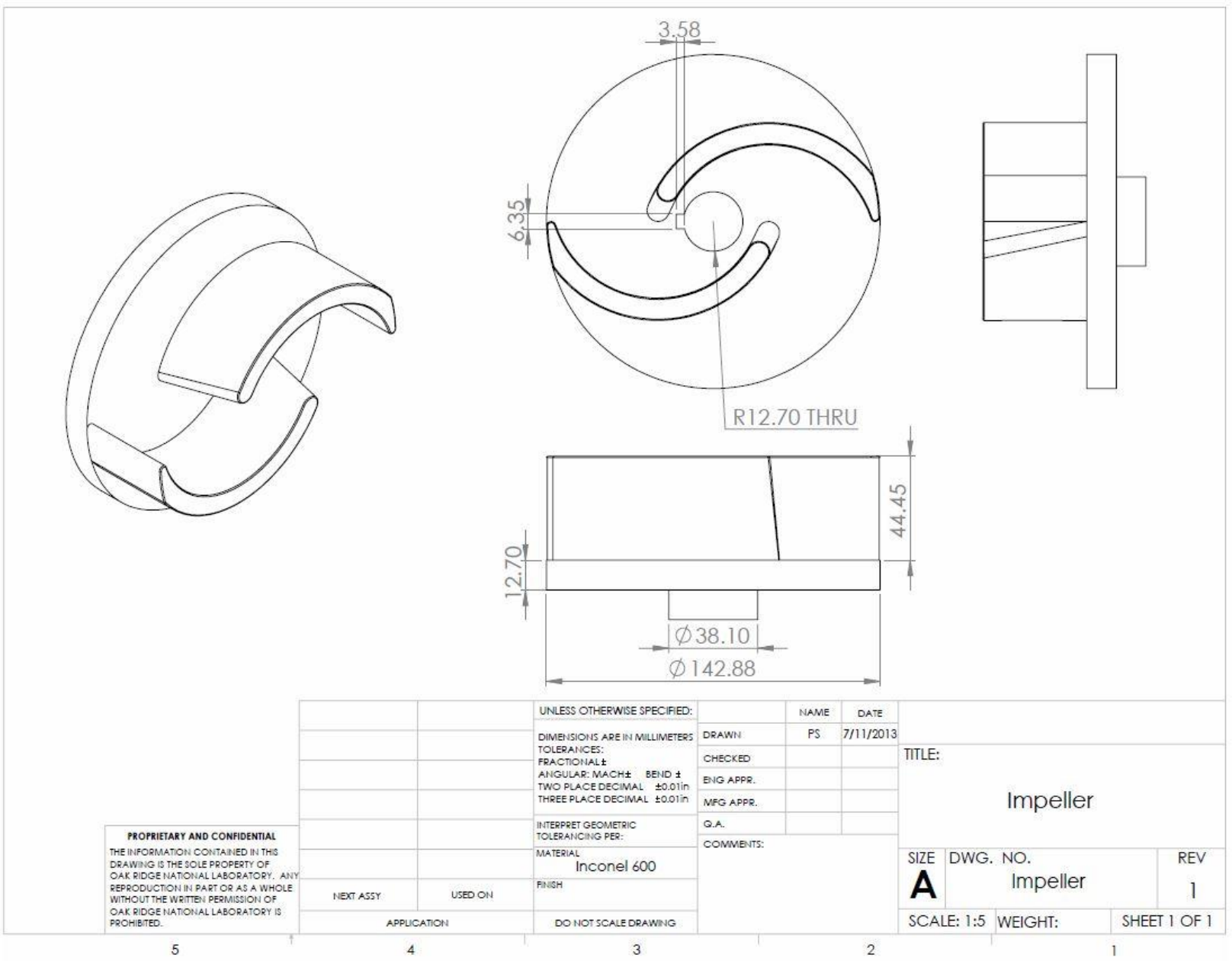




\section{A.1.3 - Component Front Rotor-Can, R-03}

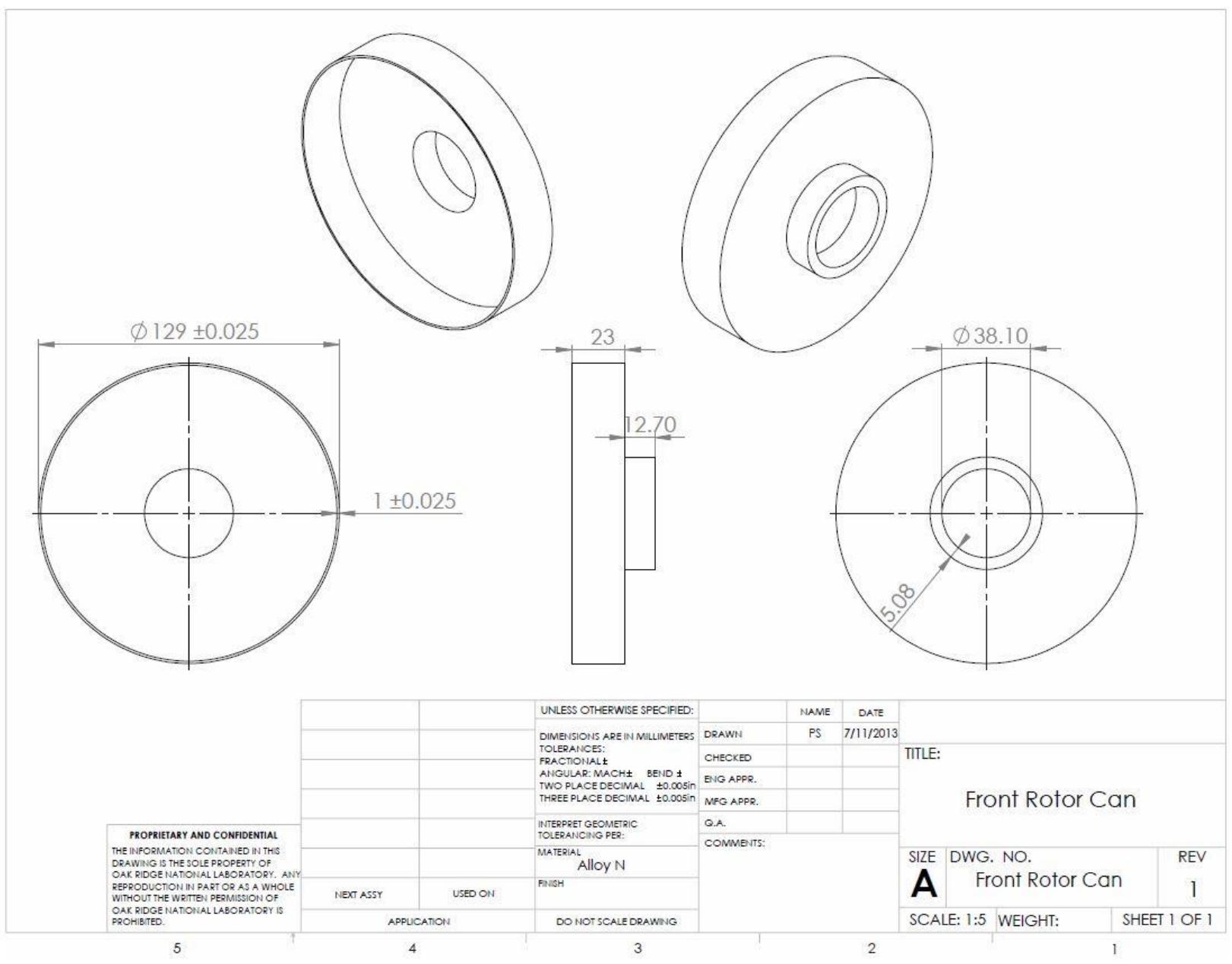




\section{A.1.4 - Component Axial bearing mount (Front and Rear), R-04, R-10}

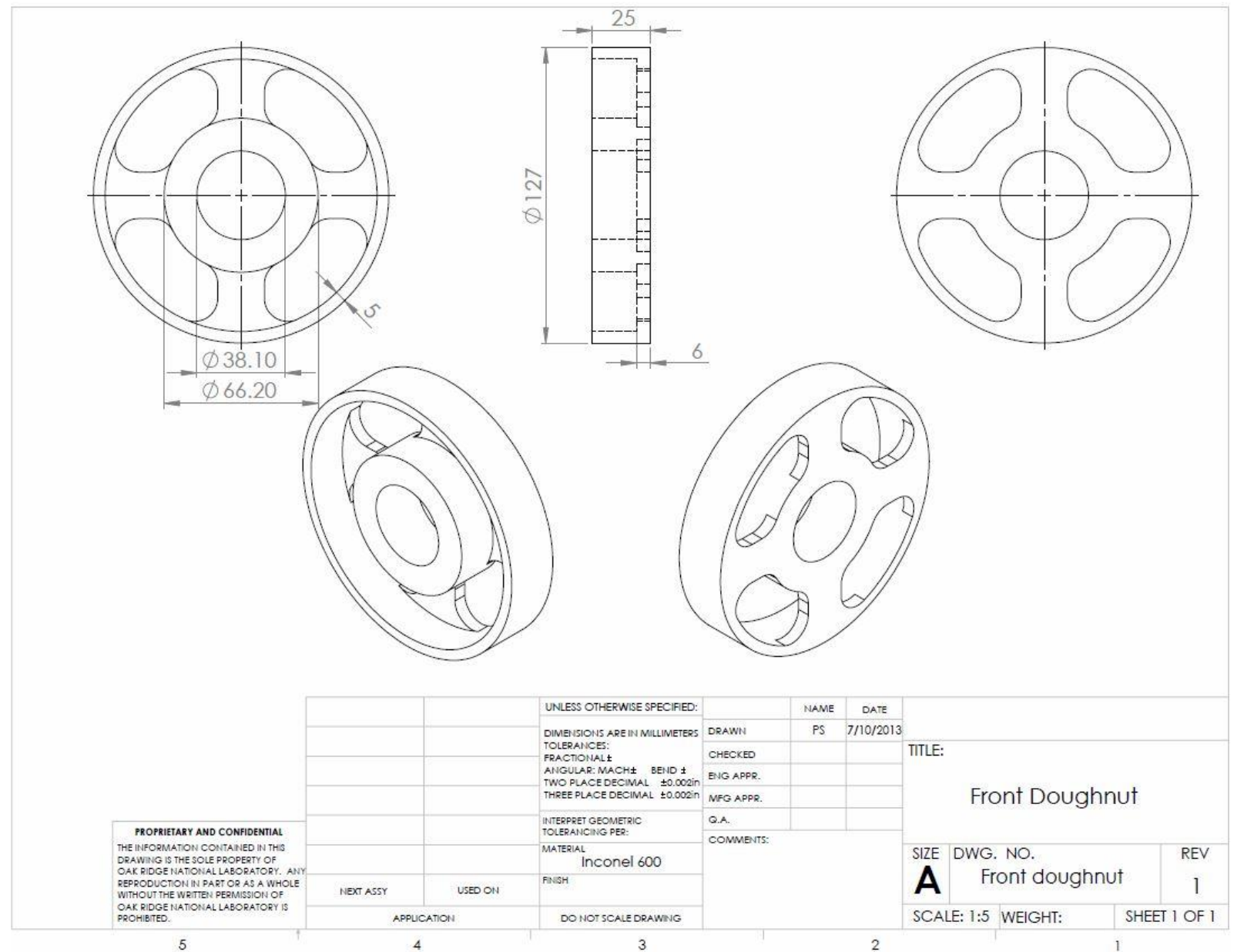




\section{A.1.5 - Component Spacer (Front, Middle Front and Middle Rear, and Rear), R-05, R0-7, R-09}

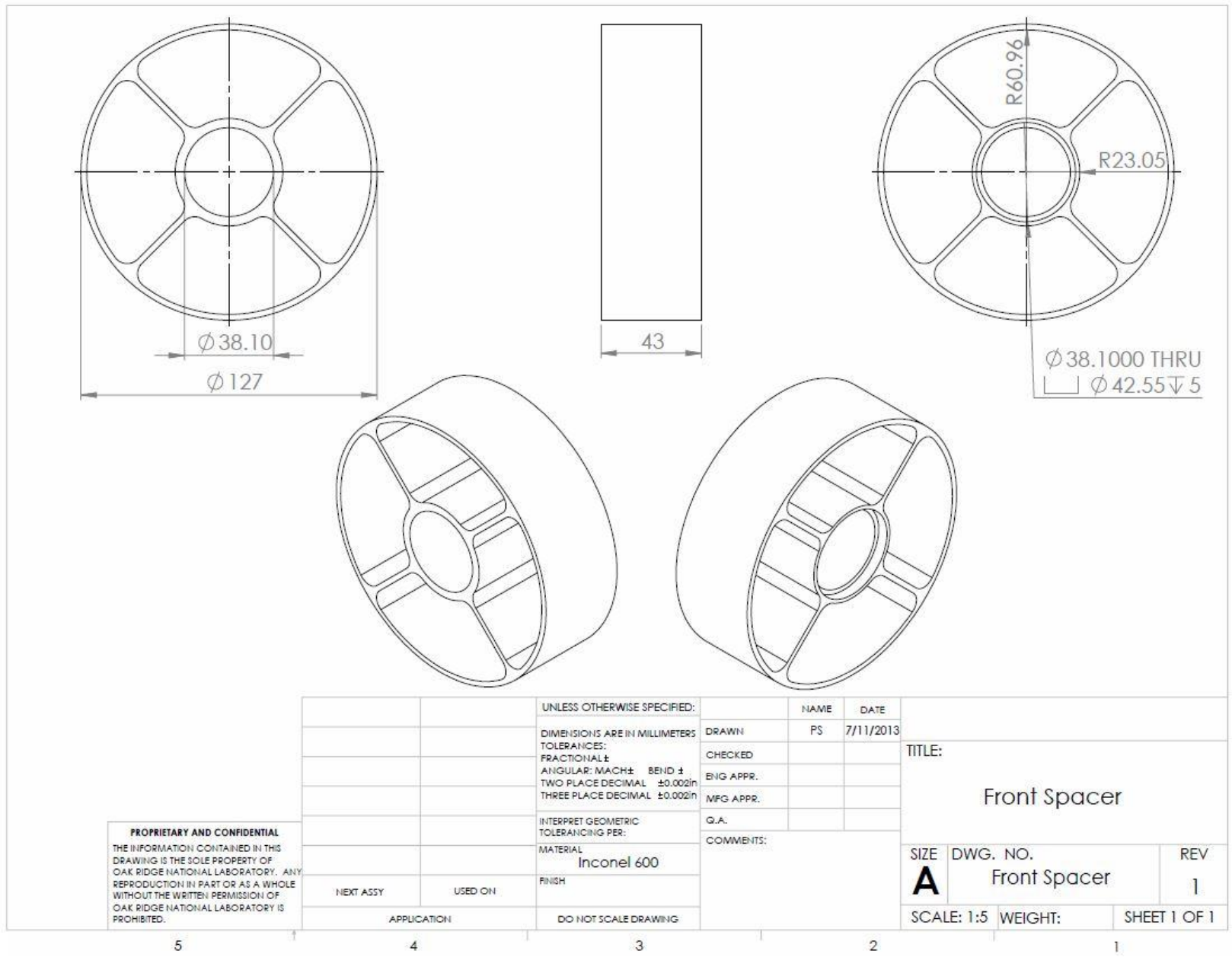




\section{A.1.6 - Component Bearing Rotor, R-06}

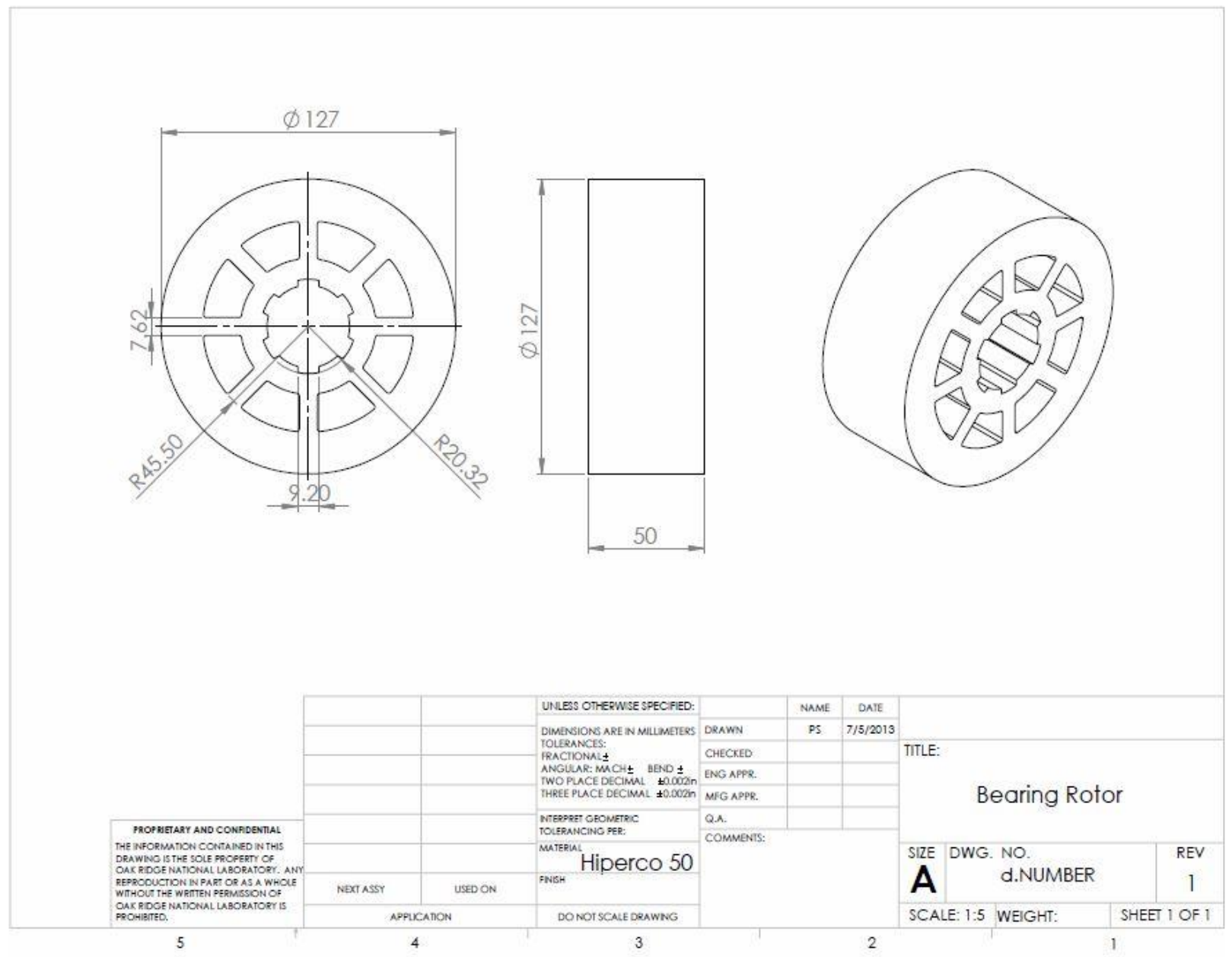




\section{A.1.7 - Component Rotor Laminations, R-08}

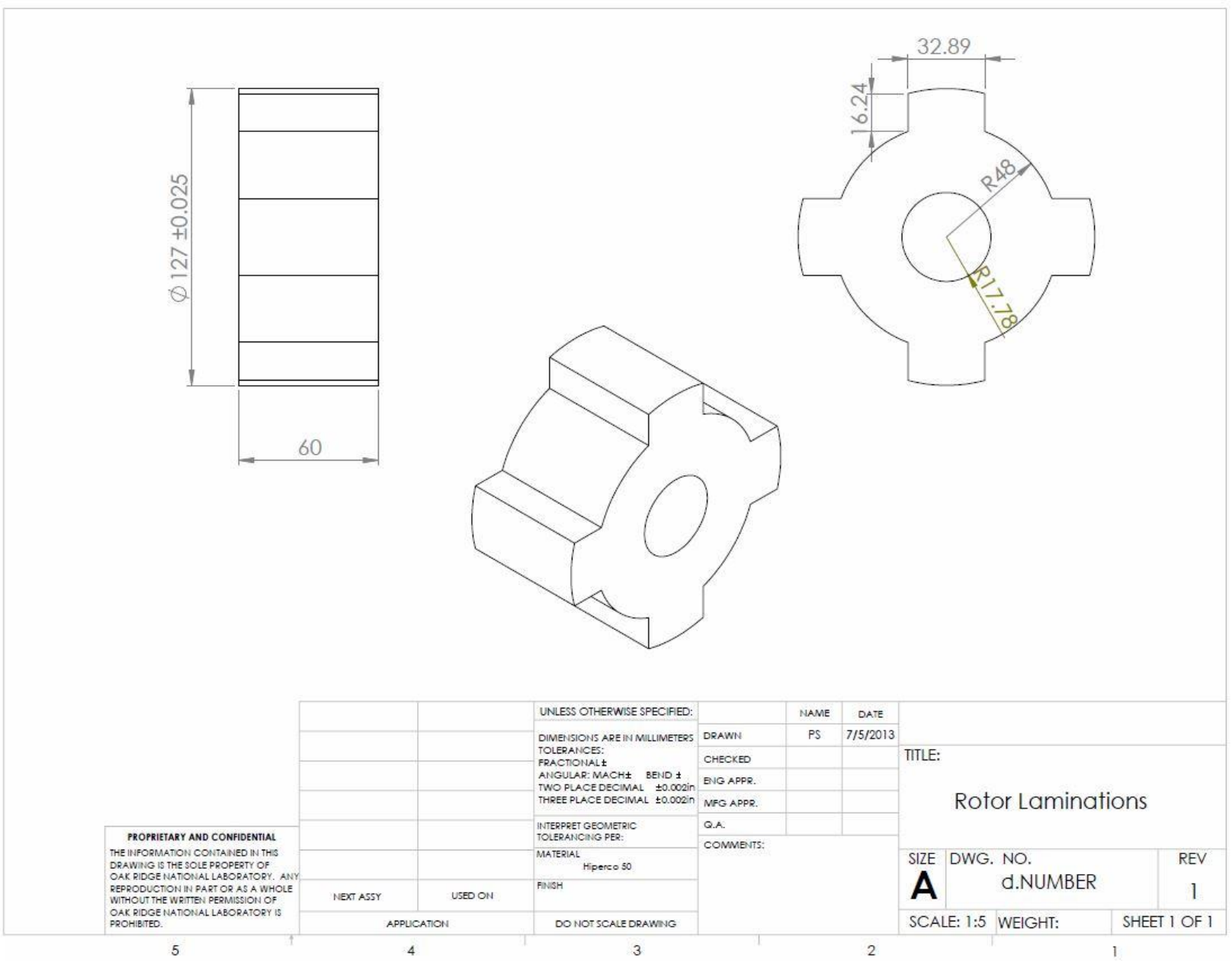




\section{A.1.8 - Component Rotor-Can Rear, R-11}

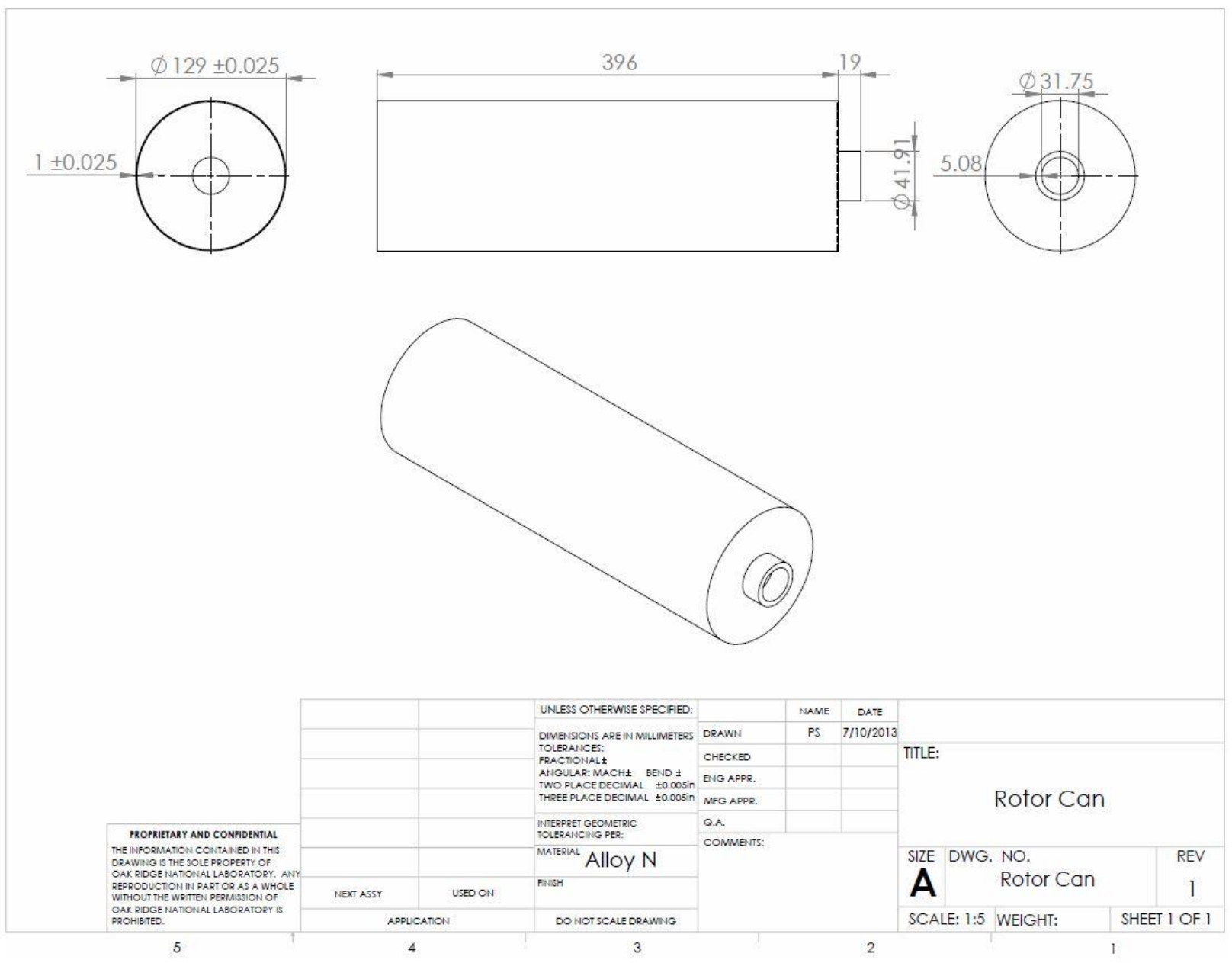




\section{A.1.9 - Component Stator-Can, S-01}

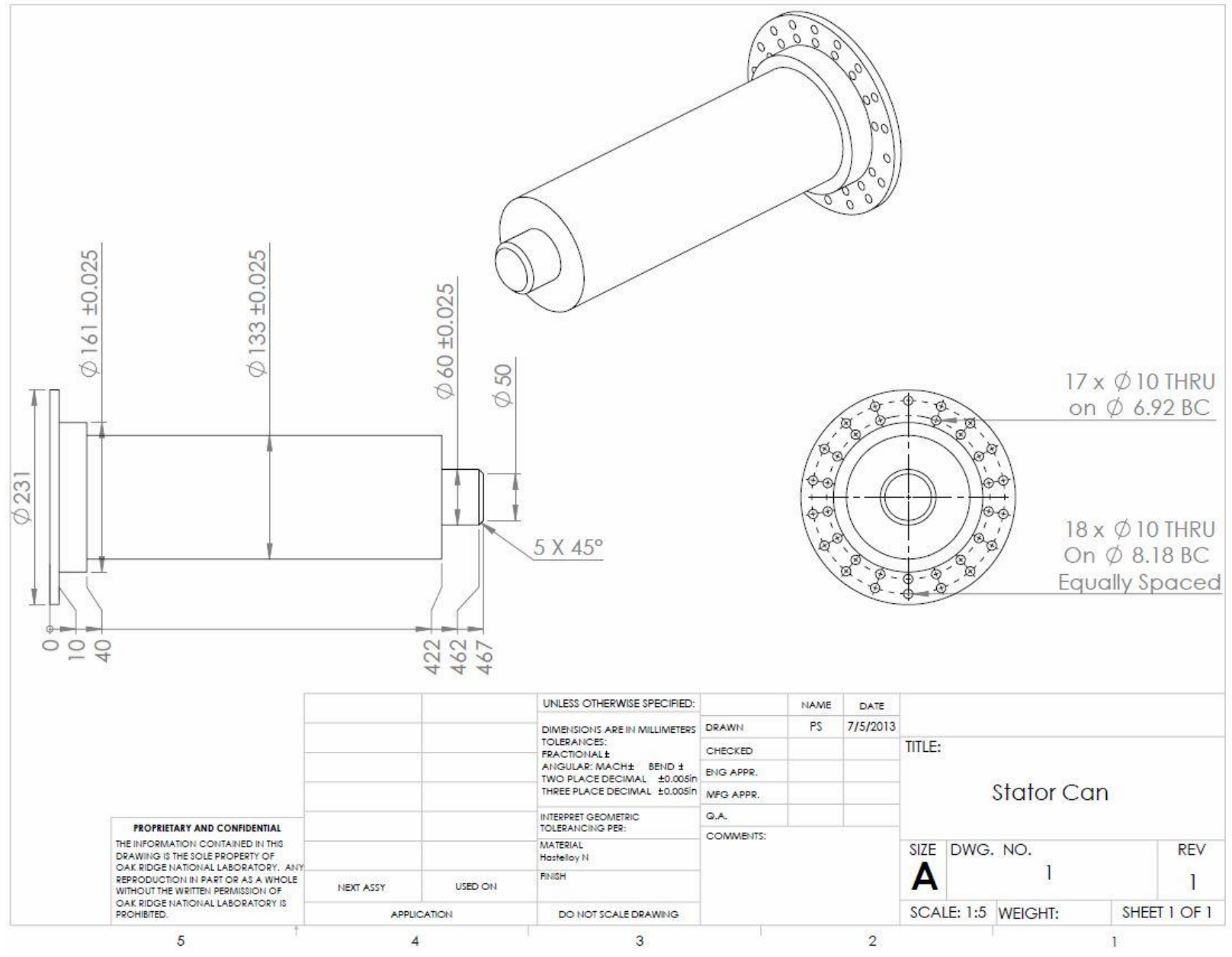




\section{A.1.10 - Component Rear Touchdown Bearing, S-02}

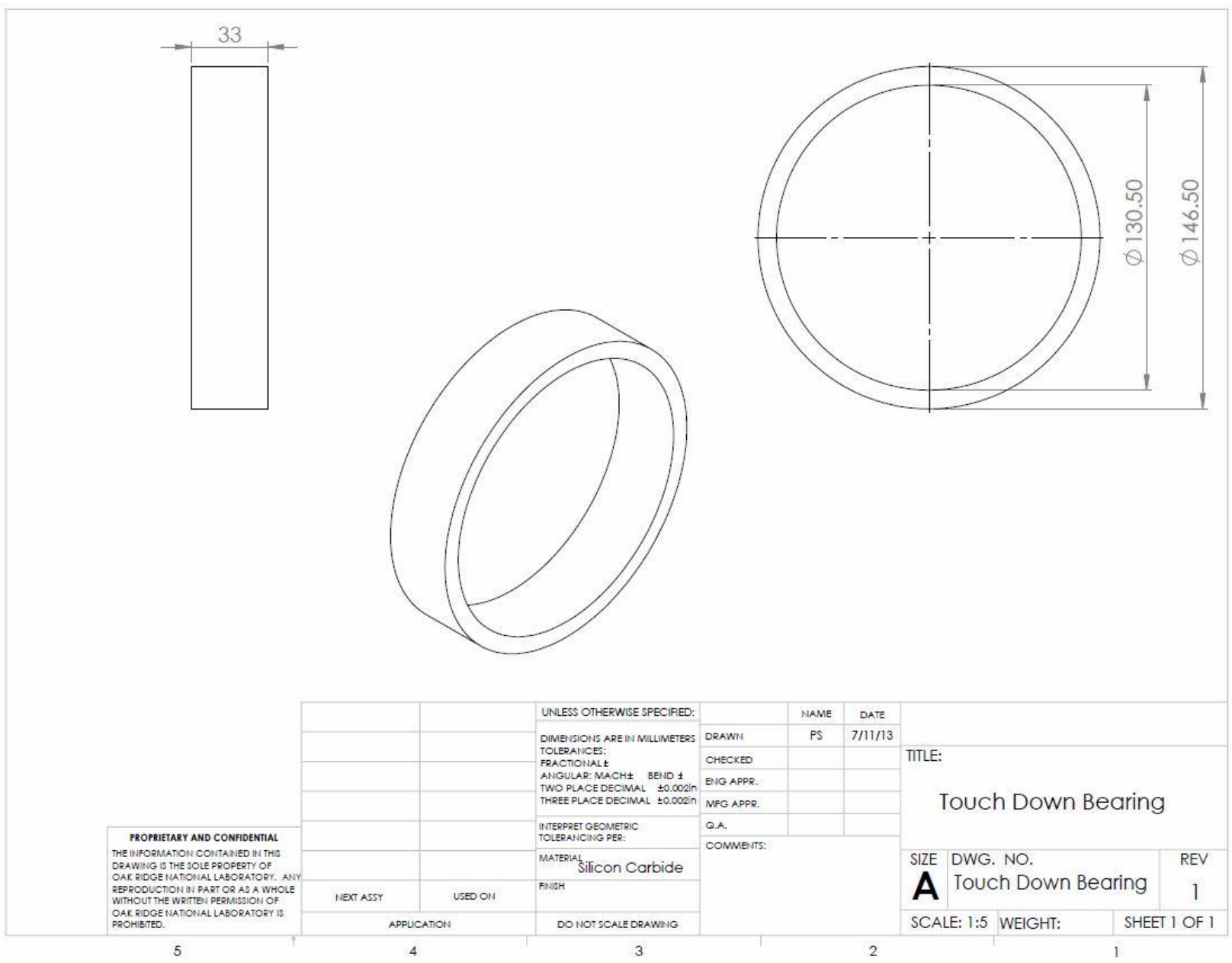




\section{A.1.11 - Component Bearing Mount (rear and front), S-03, S-07}

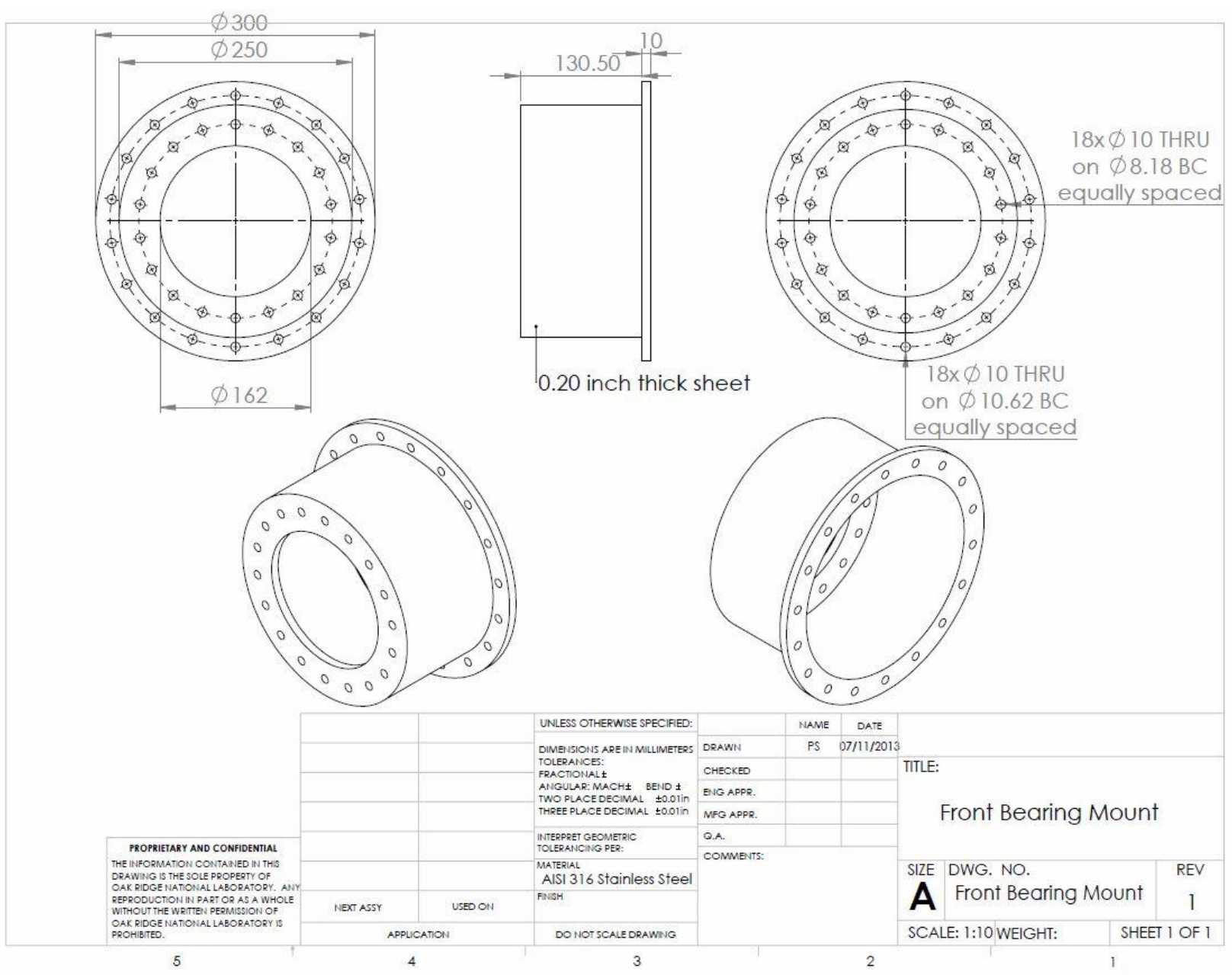




\section{A.1.12 - Component Motor Mount, S-05}

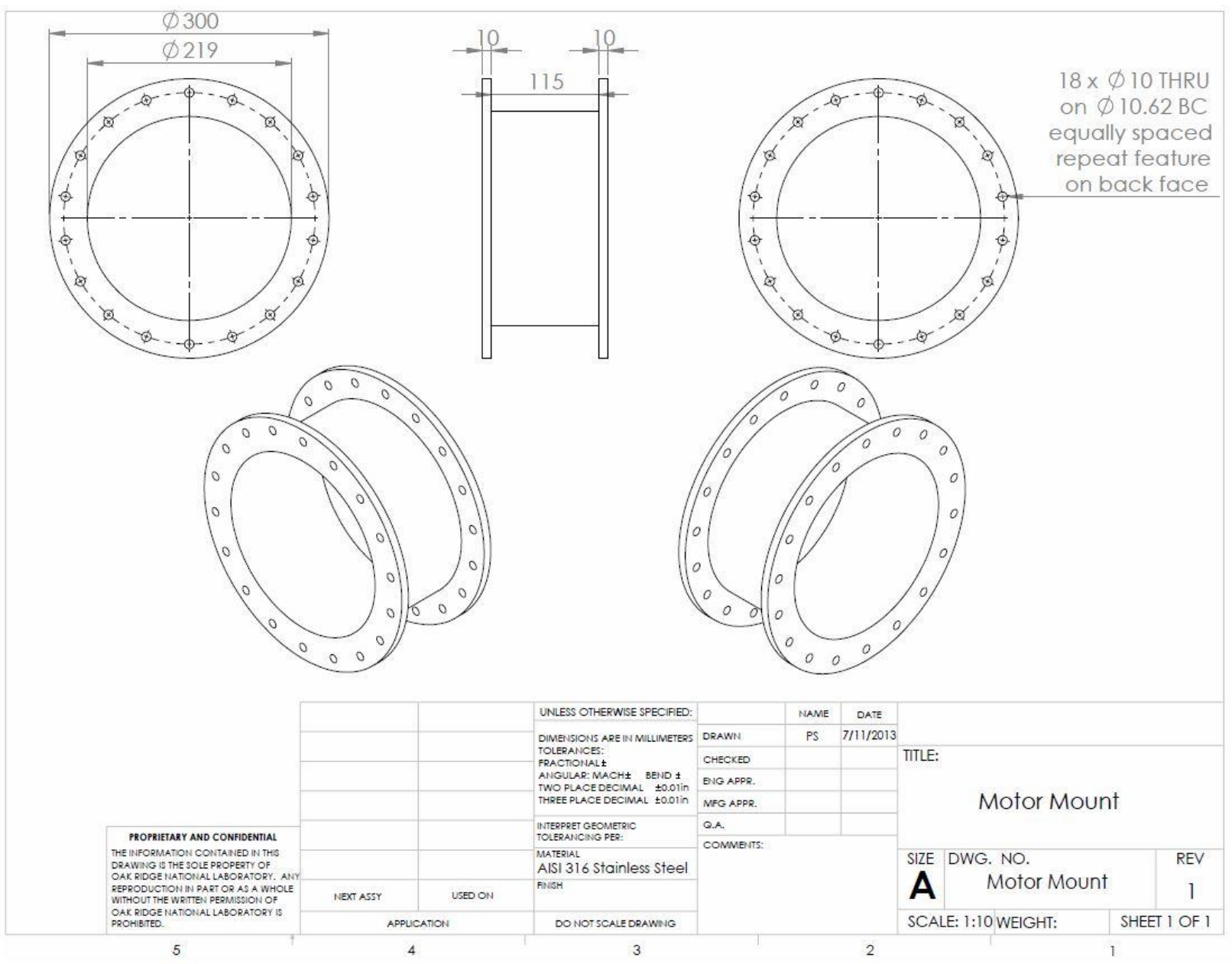




\section{A.1.13 - Component Stator Laminations (front and rear), S-06}
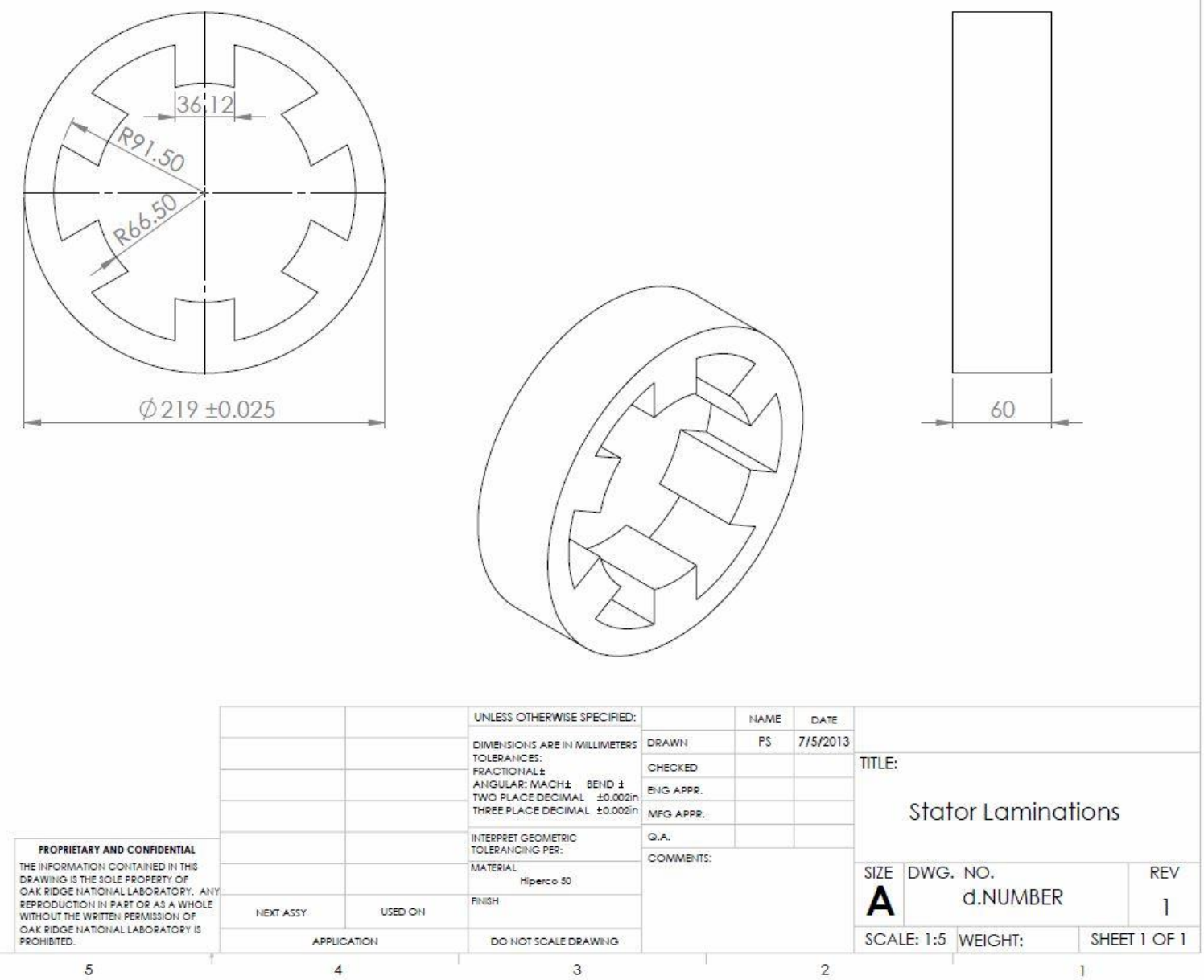


\section{A.1.14 - Component Coupler, C-01}

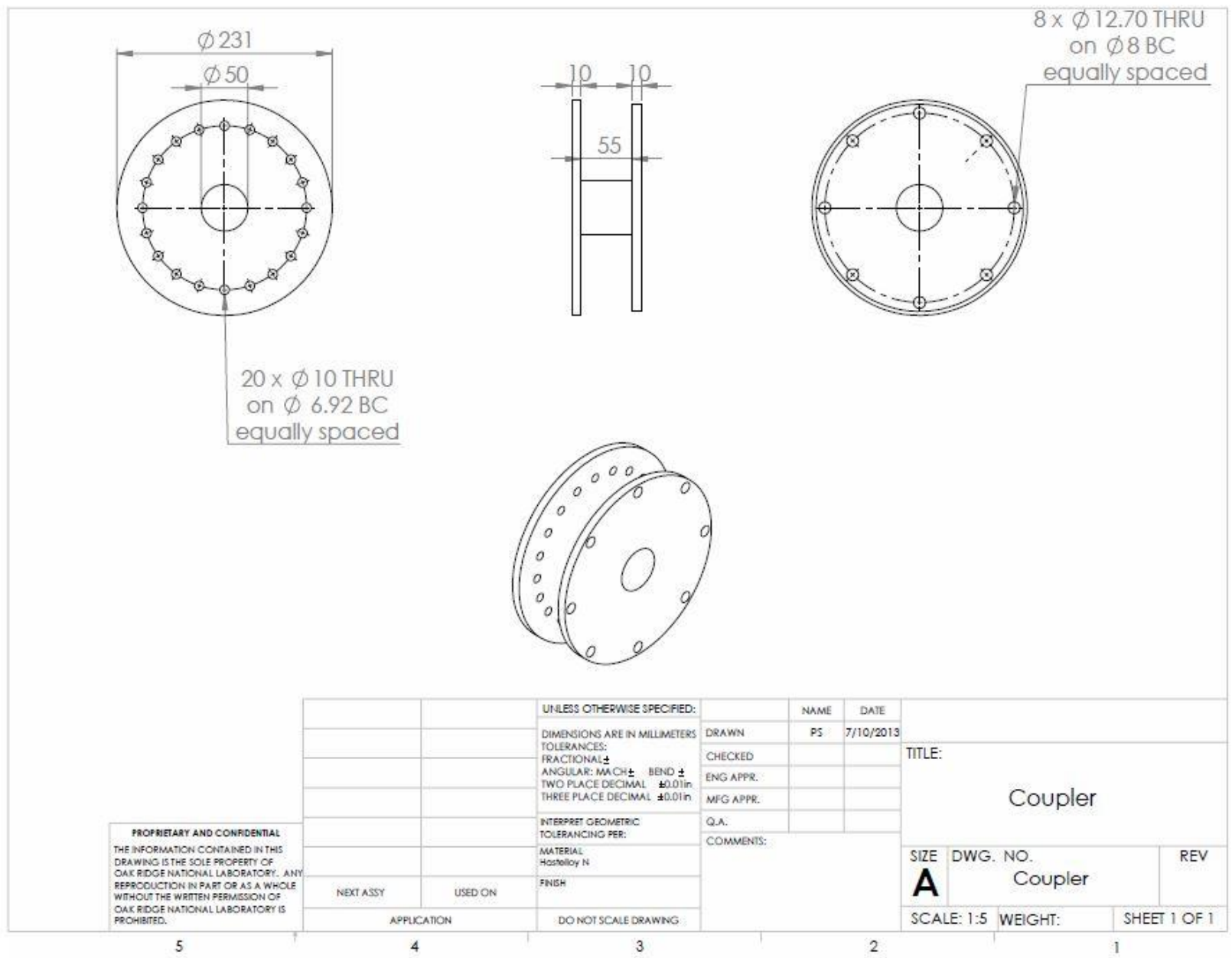




\section{A.1.15 - Component Front Touchdown Bearing, C-03}

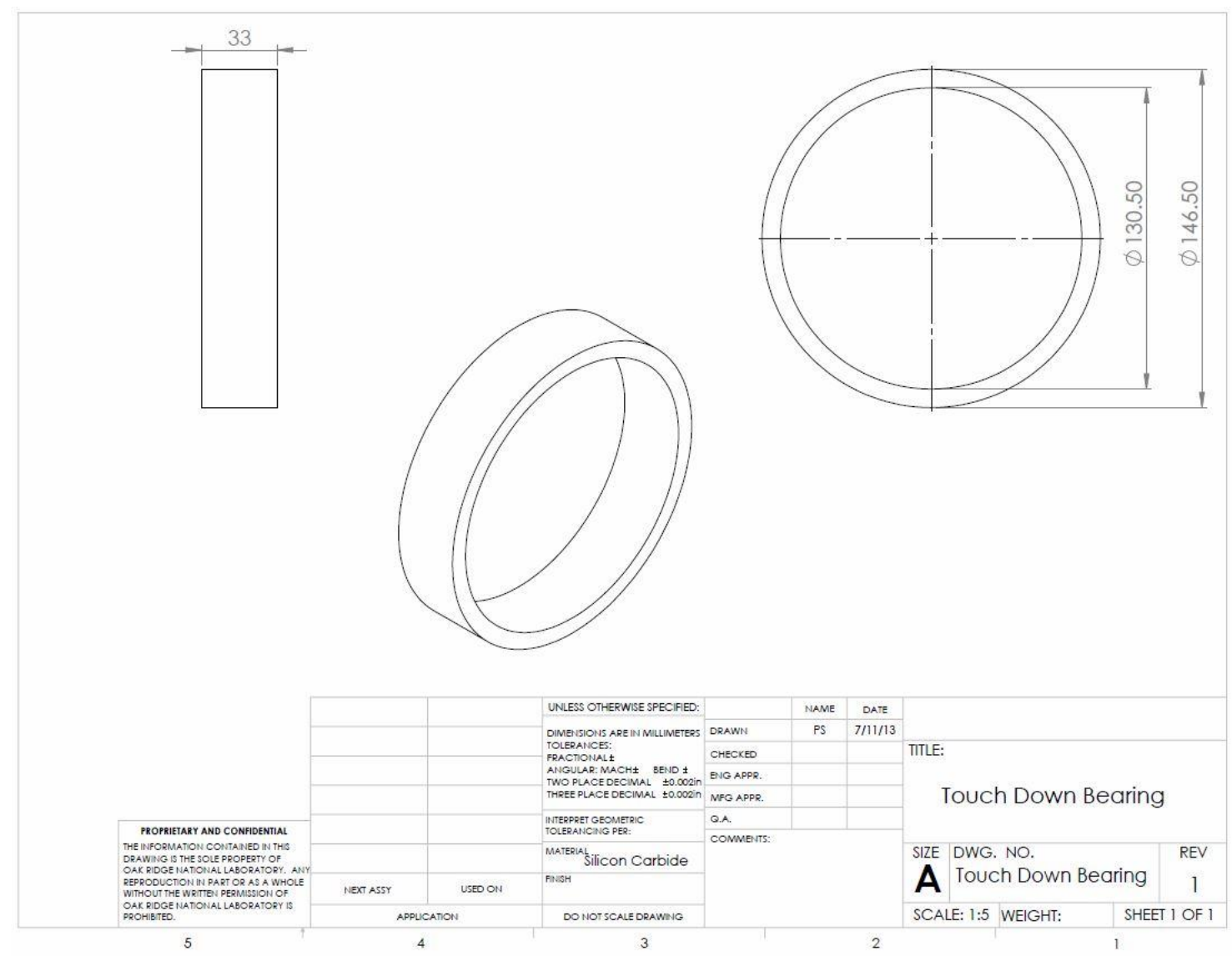




\section{A.1.16 - Component End Cap, E-01}

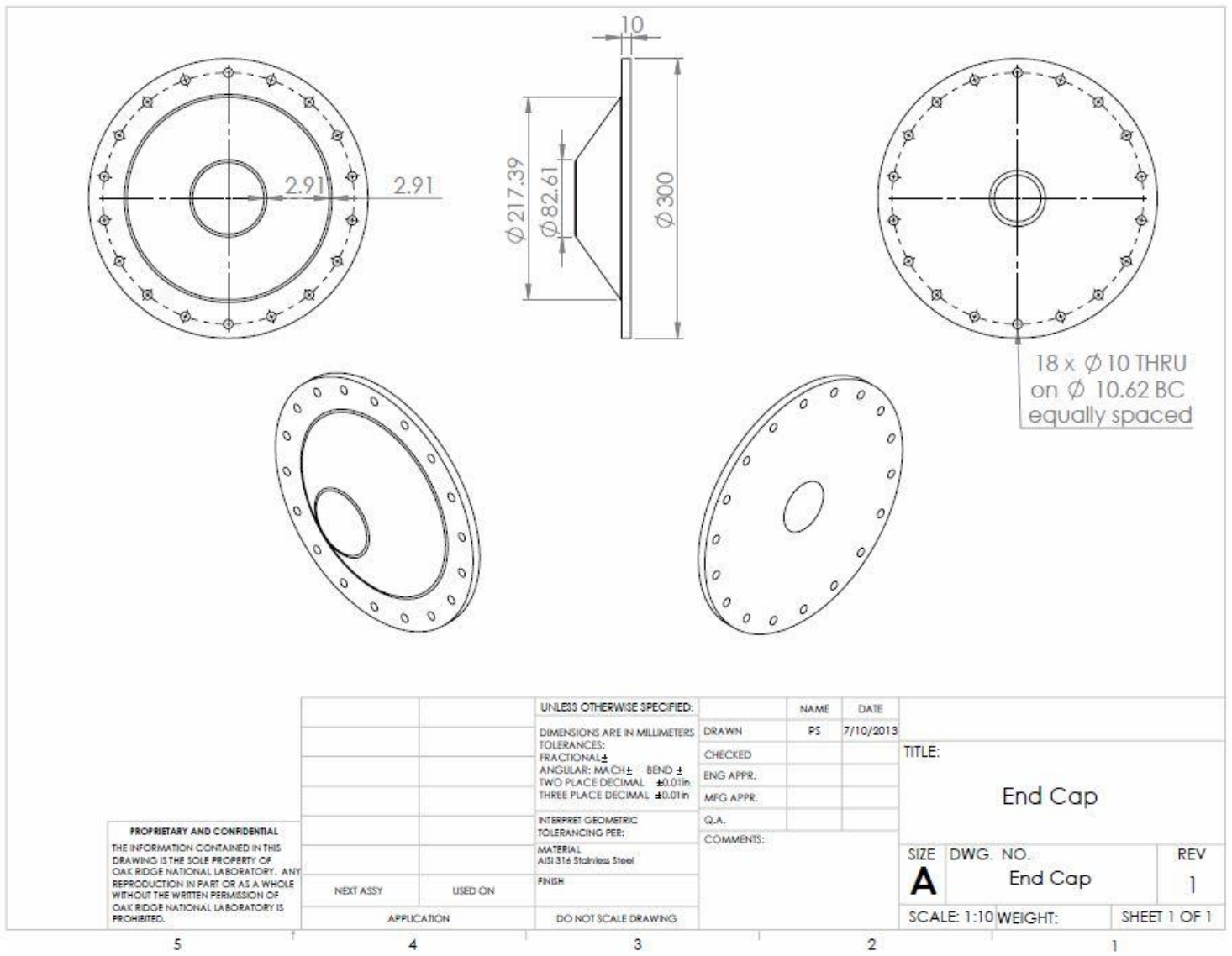




\section{A.2 COMPONENT REQUIREMENT DOCUMENTS}

Part Name Module Designation: Axle, Rotor, R-01-V0.0

Location: Center of Rotor

Description: Shaft of Rotor

Primary Function: Mechanical transfer of torque from laminations to impeller rotation

Secondary Function: Mechanical attachment for impeller, bearings, motor laminations, rotor spacers, each end of rotor-can, and fluid control

Operating Conditions

\begin{tabular}{|l|l|}
\hline Temperature & $650-700 \mathrm{C}$ \\
\hline Component dynamics & Rotational \\
\hline Speed & 3600 RPM \\
\hline Exposed to salt? & Yes \\
\hline
\end{tabular}

Load Sources and Requirements: The primary loads on the axle arise from rotor dynamic forces.

The axle stiffness needs to be designed such that the maximum axial rotor dynamic forces seen during spin-up and normal operation don't cause rubbing between the rotor and stator. The impeller forces will also be transferred to the axle, specifically, radial forces due to the suction head at the impeller inlet, and torque pulses at the impeller output due to the discrete number of blades.

Lead and alternate materials: Alloy N (Hastelloy ${ }^{\circledR}$ N) / 316 SS/ 800 H/Alloy 600/ Alloy 617

Material Considerations: Parts of the axle will be exposed to the corrosive effects of the molten salt so the axle material must withstand these effects for the lifetime of the part without affecting the part functionality.

Fabrication methods: Machining \& Grinding (Spline End may require EDM or Water Jet). The axle will be machined from bar stock. Splines will be rough ground into the axle and the axle will be heat treated afterwards to relieve grinding stress, the final grinding will be performed.

Axle balance is critical so the axle will be balanced radially.

Attached to: Base Piece

Joining options: Base Piece

Dimensional specifications (finish/tolerance): refer to Appendix A.1.1

Design \& Fabrication Issues: Material Availability, Assembly Sequence \& Distortion

Failure Modes: Chemical erosion, vibration (creep, fatigue), rubbing, salt interjection between axle and laminations, weld failure.

Other:

1. Suggestion: Concern about transition at end of spline for a square contour. Extend spline to face or rotor-can front and use a grove/snap ring or pin to locate rotor-can front for welding processes. 
Part Name, Module Designation: Impeller, Rotor, R-02-V0.0

Location: Front of motor in fluid stream

Description: Impeller on end of motor axle for pumping fluid medium

Primary Function: Mechanical transfer of torque from axle to fluid

Secondary Function: Encourage Fluid Pump, Facilitate drain of system and to function as a blower to remove salt (introduce argon, or nitrate salt, etc.) for maintenance.

Attached to: Axle R-01

Exposed to Salt? Yes

Lead and alternate materials: Alloy $\mathrm{N}\left(\right.$ Hastelloy $\left.^{\circledR} \mathrm{N}\right) / 316 \mathrm{SS} / 800 \mathrm{H}$

Fabrication methods: Machining \& Grinding (Thread Impeller or Use Fastening Nut)

Joining options: Joined to Axle Impeller End by internal threads or by spline fit and nut

Dimensional specifications (finish/tolerance): refer to Appendix A.1.2.

Design \& Fabrication Issues: Material Availability, Impeller and Case must use same material and design must provide proper fit at working temperature, Ability to remove after use/operation for maintenance (graphite thread lubricant)

Other:

1. Facilitate drain of system and to function as a blower to remove salt (introduce argon, or nitrate salt, etc.) for maintenance. 
Part Name, Module Designation: Front Rotor-Can, Rotor, R-03-V0.0

Location: Front of motor barrier between rotor and salt at axle span to impeller.

Description: Front of motor barrier between rotor and salt

Primary Function: Physical and Chemical Barrier of Salt Liquid

Secondary Function: Perhaps structural support for load on radial bearing (axial bearing mount), Hydraulic flow path surface

Operating Conditions

\begin{tabular}{|l|l|}
\hline Temperature & $650-700 \mathrm{C}$ \\
\hline Component dynamics & Rotational \\
\hline Speed & $3600 \mathrm{RPM}$ \\
\hline Exposed to salt? & YES \\
\hline
\end{tabular}

Load sources/Requirements: The rotor will prevent leakage into the rotor assembly, and must not interfere with the electromagnetic penetration necessary for the satisfactory performance of the rotor and inner bearing laminations.

The rotor-can will be exposed to fluid forces and thermal stresses, and its stiffness must ensure that maximum deflections are not exceeded, and the desired fluid gap is maintained.

Lead and alternate materials: Alloy $\mathrm{N}\left(\right.$ Hastelloy $\left.^{\circledR} \mathrm{N}\right) / 316 \mathrm{SS} / 800 \mathrm{H}$

Fabrication methods: Sheet rolled (hydroform) and welded. Tolerances in the order of 0.001 inches will be needed in order to guarantee the required fluid gap.

Attached to: Axle R-01 and Rotor-Can Rear R-11, and perhaps to rotor outer diameter components. Joining options: Joined to axle with circular weld (or vacuum base gold/nickel), Joined to rotor-can rear with circular weld and grind (weld procedure suitable for Alloy $\mathrm{N}$ )

Dimensional specifications (finish/tolerance): refer to Appendix A.1.3.

Design \& Fabrication Issues: CTE must avoid rotor penetrating Can, Material Availability, Assembly Order

Failure Modes: Leakage, crack formation and propagation, failed attachment to rotor system, vibration, creep, corrosion.

Other:

1. If Can is penetrated, Cobalt may be detected in salt fluid. 
Part Name, Module Designation: Front Axial bearing mount, Rotor, R-04-V0.0

Location: Front of motor between rotor-can front and front spacer.

Description: Supports front axial bearing magnetic material

Primary Function: Supports magnetic material for front axial bearing and transfers axial bearing forces to rotor

Secondary Function: Interface to axle, spacer, and to rotor-can front.

Attached to: Axle R-01

Exposed to Salt? No

Lead and alternate materials: Alloy $\mathrm{N}\left(\right.$ Hastelloy $\left.^{\circledR} \mathrm{N}\right) / 316 \mathrm{SS} / 800 \mathrm{H}$

Fabrication methods: Machined and ground (consider balancing aspects)

Joining options: CTE is matched to Axle, Could this float without attachment (use spline for axle interaction)? If attached, suggest vacuum braze to Axle (Is this attached to Axle or floating with another means of securement?)

Dimensional specifications (finish/tolerance): Refer to Appendix A.1.4.

Design \& Fabrication Issues: Current drawing does not appear to properly support "pie slices" of laminations. Bearing is pulled by windings, which implies load ring is on incorrect side of Axial bearing mount. Cavities are for magnetic material locations. Through-hole in cavities is for weight reduction and may not be necessary.

Use tapered slots to contain the magnetic material. Magnetic material is thin sheets with disk with bore (torus slice) geometry.

Other:

1. Need another part/drawing/design for axial bearing laminations.

2. Laminations may be radial wedges,

3. Magnetic Concerns: 1) magnetic field should only provide normal pulling force and not a breaking force (if part is rotating or if part laminations are not aligned with windings then the magnetic field could result in a vectored force) 2) Insure that magnetic pull is symmetric about the axle center line. 
Part Name, Module Designation: Spacer, Rotor, R-05-V0.0

Location: Front of motor between front radial bearing and front axial bearing mount.

Description: Determines location of front axial bearing relative to front radial bearing

Primary Function: Supports front axial bearing magnetic material

Secondary Function: TBD.

Attached to: None

Exposed to Salt? No

Lead and alternate materials: Alloy $\mathrm{N}\left(\right.$ Hastelloy $\left.^{\circledR} \mathrm{N}\right) / 316 \mathrm{SS} / 800 \mathrm{H}$

Fabrication methods: Machined and ground (consider balancing aspects)

Joining options: CTE is matched to Axle, Is this floating, or pinned to axle? Not floating - Spline is full length.

Dimensional specifications (finish/tolerance): Refer to Appendix A.1.5.

Design \& Fabrication Issues: Combine front spacer with axial bearing mount?

Other:

1. Will we add sensing features to spacer(s)?

2. If we think about the front $\&$ rear rotor-can interface: Perhaps a groove or other feature in the space outer diameter would facilitate joining each can piece if a lower tolerance manner potentially reducing or avoiding the post-weld grinding. Perhaps crimps ends of can sections into a groove or notch and then apply a finish weld bead of material? 
Part Name, Module Designation: Bearing Rotor (Front \& Back), Rotor, R-06-V0.0 (2 Instances)

Location: Front is between front spacer and the front middle spacer on the rotor. Rear is between the rear spacer and the rear middle spacer.

Description: Supports front radial bearing magnetic material

Primary Function: Transfers radial bearing forces to rotor for axle stability during rotation

Secondary Function: Determine axle position by monitoring Stator windings.

Attached to: None

Exposed to Salt? No

Lead and alternate materials: Iron Cobalt Vanadium Alloy (HiperCo 50), Boron Nitride Insulator

Fabrication methods: Standard lamination practices, Pin and press lamination sheets into one assembly, Add insulator, Assembly is splined to axle.

Joining options: CTE is matched to Axle, Is this floating, or pinned to axle? Not floating - Spline is full length.

Dimensional specifications (finish/tolerance): Refer to Appendix A.1.6.

Design \& Fabrication Issues: None.

Other:

1. Drawing does not show laminations and lamination securing feature. 
Part Name, Module Designation: Spacer (Middle Front \& Middle Rear), Rotor, R-07-V0.0 (2 Instances)

Location: Front is between front radial bearing and rotor lamination. Rear is between the rear radial bearing and the rotor lamination.

Description: Spacer between front radial bearing and rotor laminations and rotor laminations and rear radial bearing.

Primary Function: Preserve location of front radial bearing relative to motor rotor and back radial bearing.

Secondary Function: TBD.

Attached to: None

Exposed to Salt? No

Lead and alternate materials: Alloy N (Hastelloy $\left.{ }^{\circledR} \mathrm{N}\right) / 316 \mathrm{SS} / 800 \mathrm{H}$

Fabrication methods: Machined and ground (consider balancing aspects)

Joining options: CTE is matched to Axle, Is this floating, or pinned to axle? Not floating - Spline is full length.

Dimensional specifications (finish/tolerance): Refer to Appendix A.1.5.

Design \& Fabrication Issues: Spacer and Motor Rotor should fit together (plug \& socket) to fill spaces between motor poles to provide a uniform surface geometry for the can layer.

Other:

1. Will we add sensing features to spacer(s)? 
Part Name, Module Designation: Rotor Laminations, Rotor, R-08-V0.0

Location: Middle of rotor.

Description: Motoring torque on rotor.

Primary Function: Transfers circumferential forces to axle.

Secondary Function: Determine axle angular position by monitoring Stator windings, etc.

Operating Conditions

\begin{tabular}{|l|l|}
\hline Temperature & $650-700 \mathrm{C}$ \\
\hline Component dynamics & Rotational \\
\hline Speed & 3600 RPM \\
\hline Exposed to salt? & No \\
\hline
\end{tabular}

Load sources/Requirements: The rotor will be exposed to the magnetic loads which will produce the torque on the rotor.

Lead and alternate materials: Iron Cobalt Vanadium Alloy (HiperCo 50), Boron Nitride Insulator Material Considerations: A ferromagnetic material must be used such that it is affected by the induced magnetic field.

Fabrication methods: Standard lamination practices, Pin and press lamination sheets into one assembly, add insulator, Assembly is splined to axle.

Attached to: None

Joining options: CTE is matched to Axle, Is this floating, or pinned to axle? Not floating - Spline is full length.

Dimensional specifications (finish/tolerance): Refer to Appendix A.1.7

Design \& Fabrication Issues: Material (non-magnetic) is needed between magnetic poles to provide uniform support for rotor-can and to aid in balance. This could be accomplished by altering one spacer to have prongs that cover the gaps between the rotor magnetic poles and mate with the other spacer. Spline in spacer may not be necessary.

Other:

1. Drawing does not show laminations and lamination securing feature.

2. Not sure if spline is necessary. Spline could improve structural strength? 
Part Name, Module Designation: Rear Spacer, Rotor, R-09-V0.0

Location: Between rear radial bearing and rear axial bearing mount.

Description: Spacer between rear radial bearing and rear axial bearing mount.

Primary Function: Preserve location of rear radial bearing relative to motor rotor

Secondary Function: TBD.

Attached to: None

Exposed to Salt? No

Lead and alternate materials: Alloy N (Hastelloy $\left.{ }^{\circledR} \mathrm{N}\right) / 316 \mathrm{SS} / 800 \mathrm{H}$

Fabrication methods: Machined and ground (consider balancing aspects)

Joining options: CTE is matched to Axle, Is this floating, or pinned to axle? Not floating - Spline is full length.

Dimensional specifications (finish/tolerance): Refer to Appendix A.1.5

Design \& Fabrication Issues: Combine rear spacer with rear axial bearing mount?

Other:

1. None. 
Part Name, Module Designation: Rear Axial bearing mount, Rotor, R-010-V0.0

Location: Rear of motor between rear spacer and rear rotor-can.

Description: Supports rear axial bearing magnetic material

Primary Function: Supports magnetic material for rear axial bearing and transfers axial bearing forces to rotor

Secondary Function: Interface to axle, spacer, and to rear rotor-can.

Attached to: Axle R-01

Exposed to Salt? No

Lead and alternate materials: Alloy $\mathrm{N}\left(\mathrm{Hastelloy}^{\circledR} \mathrm{N}\right) / 316 \mathrm{SS} / 800 \mathrm{H}$, Ask Dane W. about iron cobalt oxide for insulation (due to not being exposed to salt)?

Fabrication methods: Machined and ground (consider balancing aspects)

Joining options: CTE is matched to Axle, Could this float without attachment (use spline for axle interaction)? If attached, suggest vacuum braze to Axle (Is this attached to Axle or floating with another means of securement?)

Dimensional specifications (finish/tolerance): Refer to Appendix A.1.4.

Design \& Fabrication Issues: Current drawing does not appear to properly support "pie slices" of laminations. Bearing is pulled by windings, which implies load ring is on incorrect side of Axial bearing mount. Cavities are for magnetic material locations. Through-hole in cavities are for weight reduction and may not be necessary.

Use tapered slots to contain the magnetic material. Magnetic material is thin sheets with disk with bore (torus slice) geometry.

Other:

1. Need another part/drawing/design for axial bearing laminations.

2. Laminations may be radial wedges,

3. Magnetic Concerns: 1) magnetic field should only provide normal pulling force and not a breaking force (if part is rotating or if part laminations are not aligned with windings then the magnetic field could result in a vectored force) 2) Insure that magnetic pull is symmetric about the axle center line. 
Part Name, Module Designation: Rotor-Can Rear, Rotor, R-11-V0.0

Location: Rear of motor barrier between rotor and salt.

Description: Rear of motor barrier between rotor and salt

Primary Function: Physical and Chemical Barrier of Salt Liquid

Secondary Function: Perhaps structural support for load on radial bearing (axial bearing mount), Hydraulic flow path surface

Operating Conditions

\begin{tabular}{|l|l|}
\hline Temperature & $650-700 \mathrm{C}$ \\
\hline Component dynamics & Rotational \\
\hline Speed & $3600 \mathrm{RPM}$ \\
\hline Exposed to salt? & Yes \\
\hline
\end{tabular}

Load sources/Requirements: The rotor will prevent leakage into the rotor assembly, and must not interfere with the electromagnetic penetration necessary for the satisfactory performance of the rotor and inner bearing laminations.

The rotor-can will be exposed to fluid forces and thermal stresses, and its stiffness must ensure that maximum deflections are not exceeded, and the desired fluid gap is maintained.

Lead and alternate materials: Alloy $\mathrm{N}\left(\right.$ Hastelloy $\left.^{\circledR} \mathrm{N}\right) / 316 \mathrm{SS} / 800 \mathrm{H}$

Fabrication methods: Sheet rolled (hydroform) and welded. Tolerances in the order of 0.001 inches will be needed in order to guarantee the required fluid gap.

Attached to: Axle R-01 and Rotor-can Front R-03, and perhaps to rotor outer diameter components. Joining options: Joined to axle with circular weld (or vacuum base gold/nickel), Joined to rotor-can rear with circular weld and grind (weld procedure suitable for Alloy $\mathrm{N}$ )

Dimensional specifications (finish/tolerance): Refer to Appendix A.1.8.

Design \& Fabrication Issues: CTE must avoid rotor penetrating Can, Material Availability, Assembly Order

Other:

1. If Can is penetrated, Cobalt may be detected in salt fluid. 
Part Name, Module Designation: Stator-Can, Stator, S-01-V0.0

Location: Front of motor between stator and salt to rear of motor

Description: Structure which protects stator coming into contact with molten salt.

Primary Function: Physical and Chemical Barrier of Salt Liquid

Secondary Function: Defines salt flow channel for coolant, Opening (plug, etc.) to permit draining of pump.

Operating Conditions

\begin{tabular}{|l|l|}
\hline Temperature & $650-700 \mathrm{C}$ \\
\hline Component dynamics & Stationary \\
\hline Speed & N/A \\
\hline Exposed to salt? & Yes \\
\hline
\end{tabular}

Load sources/Requirements: The stator-can must prevent leakage into the stator assembly, and must not interfere with the electromagnetic penetration necessary for the satisfactory performance of the rotor and inner bearing laminations. The stator-can will be exposed to fluid forces and thermal stresses, and its stiffness must ensure that maximum deflections are not exceeded, and the desired fluid gap is maintained.

Lead and alternate materials: Alloy $\mathrm{N}\left(\right.$ Hastelloy $\left.^{\circledR} \mathrm{N}\right) / 316 \mathrm{SS} / 800 \mathrm{H}$

Fabrication methods: Sheet rolled (hydroform) and welded. Tolerances in the order of 0.001 inches will be needed in order to guarantee the required fluid gap.

Attached to: Coupler C-01 and Stator.

Joining options: Hydrostatically formed into Stator assembly to fit and attach to Stator OR chill and fit (warm-up creates attachment), at back of rotor (interface with end cap) use spring loaded bolt fasteners to attach to coupler.

Dimensional specifications (finish/tolerance): Refer to Appendix A.1.9.

Design \& Fabrication Issues: Weld bead on outside to avoid seam/bead affecting inside. How is end (back of rotor) secured or located? Brazed drain plug on back end to enable draining.

Failure Modes: Leakage, crack formation and propagation, failed attachment to stator system, failed axial bearing attachment, vibration, creep, corrosion.

Other:

1. Special tool to support inside (piston) to avoid distortion during insertion. After attachment, tool is removed.

2. Need means to drain pump of salt.

3. Coupler to Stator-Can interface must not leak salt! 
Part Name, Module Designation: Rear Touchdown Bearing, Stator, S-02

Location: between Rotor-can Rear \& Stator-Can

Description: Radial touchdown bearing at rear of rotor.

Primary Function: Protect Rotor-can when control is lost

Secondary Function: Protect rotor when pump stops.

Attached to: Floating

Exposed to Salt? Yes

Lead and alternate materials: (1) cast ceramic with finish grinding or machined graphite bearing to provide surface and tolerances.

(2) Continuous Fiber Composite (CFC) SiC/CC, or Graphite,

(3) Could be metal piece with ceramic or graphite inserts.

Fabrication methods: Will probably be cast to specific dimensions (does casting provide proper tolerances), Intended to float, Slot or groove in Stator-Can to facilitate a base that slides into the Stator-Can and protrudes out providing a Rotor gap,

Joining options: Floating

Dimensional specifications (finish/tolerance): Refer to Appendix A.1.10.

Design \& Fabrication Issues: Will require a matched set to obtain proper clearance. May need multiple sets (of different dimensions) to provide an adjustment.

Other:

1. Pay attention to adjustment needs. 
Part Name, Module Designation: Rear Bearing Mount, Stator, S-03

Location: Between End Cap and Motor Mount

Description: Rear stator enclosure.

Primary Function: Mounting structure for stator and stator magnetics and windings.

Secondary Function: Thermal effects - we need to keep windings at temperature but not over temperature.

Attached to: End Cap and Motor Mount

Exposed to Salt? No

Lead and alternate materials: $316 \mathrm{SS}$

Fabrication methods: Sheet rolled (hydroform) and welded.

Joining options: Bolted fasteners to End Cap and Motor Mount.

Dimensional specifications (finish/tolerance): Refer to Appendix A.1.11.

Design \& Fabrication Issues: None

Other:

1. Pay attention to adjustment needs. 
Part Name, Module Designation: Rear (Radial) Bearing (Windings), Stator, S-04

Location: Between End Cap and Rotor Laminations.

Description: Rear radial bearing windings.

Primary Function: Mounting structure for rear bearing windings.

Secondary Function: Thermal effects - we need to keep windings at temperature but not over temperature.

Attached to: Not Sure?

Exposed to Salt? No

Lead and alternate materials: Iron Cobalt Vanadium Alloy (HiperCo 50), Boron Nitride Insulator, Stator windings should be high temperature wire (glass coated copper),

Fabrication methods: Standard lamination practices.

Joining options: Standard lamination practices.

Dimensional specifications (finish/tolerance): Dim TBD (Straight, Square, etc.)

Design \& Fabrication Issues: Estimate of number of turns, electrical current, etc. will determine wire gauge and the space requirements.

Area beneath windings will have thermal insulation to protect winding temperature. Perhaps a heater device between winding insulation and the stator-can to heat up to desired temperature (above salt melt point).

Stator/Rotor parallelism encourages less rigorous axial positioning of the stator windings to the rotor magnetic material.

Other:

1. Need better drawing of rear bearing stator magnetic material \& windings. 
Part Name, Module Designation: Motor Mount, Stator, S-05

Location: Between rear bearing and front bearing

Description: Middle stator enclosure.

Primary Function: Mounting structure for stator and stator magnetics and windings.

Secondary Function: Thermal effects - we need to keep windings at temperature but not over temperature.

Operating Conditions

\begin{tabular}{|l|l|}
\hline Temperature & $650-700 \mathrm{C}$ \\
\hline Component dynamics & Stationary \\
\hline Speed & N/A \\
\hline Exposed to salt? & No \\
\hline
\end{tabular}

Load sources/Requirements: The mount will be exposed to all gravitational loads of the stator assembly. Stiffness must be designed such that maximum deflections are not exceeded. Mount may be exposed to vibration in the case of radial bearing and catcher bearing failure. Vibrations must be isolated such that the outside reactor equipment is not affected.

Lead and alternate materials: $316 \mathrm{SS}$

Fabrication methods: Sheet rolled (hydroform) and welded.

Attached to: End Cap and Motor Mount

Joining options: Bolted fasteners to End Cap and Motor Mount.

Dimensional specifications (finish/tolerance): Dim Appendix A.1.12.

Design \& Fabrication Issues: None

Failure Modes: Mechanical failure, fluid leakage, detachment of stator assembly.

Other:

1. Pay attention to adjustment needs. 
Part Name, Module Designation: Stator Windings (Laminations), S-06

Location: Between rear and front radial bearings.

Description: Incorporates the stator windings, which produces the necessary magnetic field for torque production.

Primary Function: Mounting structure for stator windings.

Secondary Function: Thermal effects - we need to keep windings at temperature but not over temperature.

Operating Conditions

\begin{tabular}{|l|l|}
\hline Temperature & $650-700 \mathrm{C}$ \\
\hline Component dynamics & Stationary \\
\hline Speed & N/A \\
\hline Exposed to salt? & No \\
\hline
\end{tabular}

Load sources/Requirements: The stator is a stationary component of the system, and must remain fixed to the motor housing. It will be exposed to the static (and electric?) loads of the current windings, as well as the induced magnetic field.

Lead and alternate materials: Iron Cobalt Vanadium Alloy (HiperCo 50), Boron Nitride Insulator, Stator windings should be high temperature wire (glass coated copper)

Material Considerations: The stator laminations must be made of a ferromagnetic material such that the magnetic field can travel through it.

Windings will require thermal insulation.

Fabrication methods: Standard lamination practices.

Joining options: Standard lamination practices.

Dimensional specifications (finish/tolerance): Refer to Appendix A.1.13.

Design \& Fabrication Issues: Estimate of number of turns, electrical current, etc. will determine wire gauge and the space requirements.

Area beneath windings will have thermal insulation to protect winding temperature. Perhaps a heater device between winding insulation and the stator-can to heat up to desired temperature (above salt melt point).

Stator/Rotor parallelism encourages less rigorous axial positioning of the stator windings to the rotor magnetic material.

Failure Modes: Lamination detachment, crack formation in laminations, incorrect or insufficient current injection, magnetic losses, detachment from stator assembly, creep, motor-stator rubbing.

Other:

1. Need better drawing of stator magnetic material \& windings. 
Part Name, Module Designation: Front Bearing Mount, Stator, S-07

Location: Between Motor Mount and Stator-Can lip

Description: Front stator enclosure.

Primary Function: Mounting structure for stator and stator front radial bearing magnetics and windings.

Secondary Function: Thermal effects - we need to keep windings at temperature but not over temperature.

Attached to: End Cap and Motor Mount

Exposed to Salt? No

Lead and alternate materials: $316 \mathrm{SS}$

Fabrication methods: Sheet rolled (hydroform) and welded.

Joining options: Bolted fasteners to End Cap and Motor Mount.

Dimensional specifications (finish/tolerance): Refer to Appendix A.1.11.

Design \& Fabrication Issues: None

Other:

1. Pay attention to adjustment needs. 
Part Name, Module Designation: Coupler, Coupler C-01

Location: Front of motor between motor and impeller

Description: Join pump case to impeller case. Supporting structure to front axial bearing.

Primary Function: Join pump case to impeller case

Secondary Function: Vital to preserve alignment of stator to rotor, Seal to pump case and impeller case, Orient pump relative to impeller case \& piping, Possible sensor location (differential from motoring sensor), Drain plug for pre-heating and maintenance.

\section{Operating Conditions}

\begin{tabular}{|l|l|}
\hline Temperature & $650-700 \mathrm{C}$ \\
\hline Component dynamics & Stationary \\
\hline Speed & N/A \\
\hline Exposed to salt? & Yes \\
\hline
\end{tabular}

Lead and alternate materials: Alloy N (Hastelloy ${ }^{\circledR} \mathrm{N}$ ) / $316 \mathrm{SS} / 800 \mathrm{H}$

Material Considerations: Coupler will be exposed to fluid; hence a non-corrosive material must be used.

Fabrication methods: Sheet rolled (hydroform) and welded, Two flat plates joined (welded) to tube center and machined/ground true (flat and square), Suggest using cupped geometry instead of flat plates (less demanding geometry), On the other hand - front axial bearing coils and insulation and process heating may be located in coupler which would lead to a thicker cross-section.

Attached to: Impeller case and pump case via Stator-Can S-01

Joining options: Bolted to pump case and impeller case, Fastener bolts must have CTE match to case and other parts and/or spring loaded.

Dimensional specifications (finish/tolerance): Refer to Appendix A.1.14.

Design \& Fabrication Issues: Requires heating to avoid salt solidification. Requires spring-loaded nickel gaskets.

Failure Modes: Mechanical failure, detachment from mount, impeller housing or axial bearing.

Other:

1. None. 
Part Name, Module Designation: Front Axial Bearings, Coupler C-02

Location: between Rotor-Can Front \& Coupler

Description: Front axial bearing windings.

Primary Function: Provide magnetic force on front axial bearing on rotor

Secondary Function: Provide energy to warm structure as pump is transitioned to startup. Located between Rotor-Can Front \& Coupler.

Operating Conditions

\begin{tabular}{|l|l|}
\hline Temperature & $650-700 \mathrm{C}$ \\
\hline Component dynamics & Stationary \\
\hline Speed & N/A \\
\hline Exposed to salt? & No \\
\hline
\end{tabular}

Lead and alternate materials: Alloy $\mathrm{N}\left(\operatorname{Hastelloy}^{\circledR} \mathrm{N}\right)$ / $316 \mathrm{SS} / 800 \mathrm{H}$, Windings are High

Temperature wire w/ glass encapsulation

Fabrication methods: Inlay split ring shape of insulating layer, bearing \& windings into Coupler.

Attached to: Coupler C-01

Joining options: Tight fit cold and loose fit hot with backing plate (CTE matched to Coupler) that is attached with fasteners into Coupler.

Dimensional specifications (finish/tolerance): Dim TBD (Straight, Square, etc.)

Design \& Fabrication Issues: Bearing/windings must be integral to Coupler, windings must avoid Coupler/salt temperature, geometry limits choice for bearing/winding shape and CTE limits attachment options.

Brazed plug or section of pipe connected to external heating and draining.

Other:

1. Windings may be in a split ring, or segments, or pie slices to achieve control axial forces.

2. Do windings include iron-core laminations? Suggest four sets of windings (quadrants) with each set wound parallel to magnetic material. Single axial windings offset radially from center and distributed at 90 degree intervals.

3. Can bearing windings provide energy to the magnetic materials that will warm the axial bearing mount, rotor-can, etc. (salt path)? We want to heat up structure while minimizing coil heating (coils will be insulated from salt at high temperature)!

4. Control of four quadrants may be a general low frequency pull tension value plus a small signal higher frequency value to adjust for axle tilt.

5. Bearing field only penetrates one can layer (rotor-can). 
Part Name, Module Designation: Front Touchdown Bearing, Coupler C-03

Location: between Rotor-Can Front \& Stator-Can

Description: Radial touchdown bearing at front of rotor.

Primary Function: Protect Rotor-Can when control is lost

Secondary Function: Protect rotor when pump stops.

Attached to: Floating

Lead and alternate materials: (1) cast ceramic with finish grinding or machined graphite bearing to provide surface and tolerances.

(2) Continuous Fiber Composite (CFC) SiC/CC, or Graphite,

(3) Could be metal piece with ceramic or graphite inserts.

Fabrication methods: Will probably be cast to specific dimensions (does casting provide proper tolerances), Intended to float, Slot or groove in Stator-Can to facilitate a base that slides into the Stator-Can and protrudes out providing a Rotor gap,

Joining options: Floating

Dimensional specifications (finish/tolerance): Refer to Appendix A.1.15.

Design \& Fabrication Issues: Will require a matched set to obtain proper clearance. May need multiple sets (of different dimensions) to provide an adjustment.

Other:

1. Pay attention to adjustment needs. 
Part Name, Module Designation: End Cap, End Cap, E-01

Location: Rear most position of motor

Description: Encloses rear section of rotor.

Primary Function: Position axial windings, containment and protection of stator-can.

Secondary Function: Part of outer structure and attaches to rear bearing mount (case).

Exposed to Salt? Yes

Lead and alternate materials: $316 \mathrm{SS}$

Fabrication methods: Sheet rolled (hydroform) and welded,

Include rear axial bearing windings in end cap piece.

Rear axial bearing coils and insulation and process heating may be located in end cap which would lead to a thicker cross-section.

Attached to: Rear bearing mount

Joining options: Bolted fasteners to rear bearing mount.

Dimensional specifications (finish/tolerance): Refer to Appendix A.1.16.

Design \& Fabrication Issues: Requires heating to avoid salt solidification on stator-can.

Other:

1. Pay attention to adjustment needs. 
Part Name, Module Designation: Rear Axial Bearings, End Cap, E-02

Location: Between Stator-Can \& End Cap

Description: rear axial bearing windings.

Primary Function: Provide axial force on rear axial bearing on rotor

Secondary Function: Provide energy to warm structure as pump is transitioned to startup.

Attached to: End Cap

Exposed to Salt? No

Lead and alternate materials: Alloy $\mathrm{N}\left(\operatorname{Hastelloy}^{\circledR} \mathrm{N}\right)$ / $316 \mathrm{SS} / 800 \mathrm{H}$, Windings are High

Temperature wire w/ glass encapsulation

Fabrication methods: Inlay split ring shape of insulating layer, bearing \& windings into End Cap.

Joining options: Tight fit cold and loose fit hot with backing plate (CTE matched to End Cap) that is attached with fasteners into End Cap.

Dimensional specifications (finish/tolerance): Dim TBD (Straight, Square, etc.)

Design \& Fabrication Issues: Bearing/windings must be integral to Coupler, windings must avoid End Cap /salt temperature, geometry limits choice for bearing/winding shape and CTE limits attachment options.

Brazed plug or section of pipe connected to external heating and draining.

Other:

1. Windings may be in a split ring, or segments, or pie slices to achieve control axial forces.

2. Do windings include iron-core laminations? Suggest four sets of windings (quadrants) with each set wound parallel to magnetic material. Single axial windings offset radially from center and distributed at 90 degree intervals.

3. Can bearing windings provide energy to the magnetic materials that will warm the axial bearing mount, rotor-can, etc. (salt path)? We want to heat up structure while minimizing coil heating (coils will be insulated from salt at high temperature)!

4. Control of four quadrants may be a general low frequency pull tension value plus a small signal higher frequency value to adjust for axle tilt.

5. Bearing field penetrates two can layers (rotor-can and stator-can). 